\title{
Cholinergic modulation of cognitive processing: insights drawn from computational models
}

\author{
Ehren L. Newman*, Kishan Gupta, Jason R. Climer, Caitlin K. Monaghan and Michael E. Hasselmo
}

Center for Memory and Brain, Boston University, Boston, MA, USA

\section{Edited by:}

Anita Disney, Salk Institute for

Biological Studies, USA

Reviewed by:

Gregg Stanwood, Vanderbilt

University, USA

Sylvie Granon, Université Paris

sud XI, France

${ }^{*}$ Correspondence:

Ehren L. Newman, Center for

Memory and Brain, 2 Cummington

St., Boston, MA 02215, USA.

e-mail: enewman@gmail.com
Acetylcholine plays an important role in cognitive function, as shown by pharmacological manipulations that impact working memory, attention, episodic memory, and spatial memory function. Acetylcholine also shows striking modulatory influences on the cellular physiology of hippocampal and cortical neurons. Modeling of neural circuits provides a framework for understanding how the cognitive functions may arise from the influence of acetylcholine on neural and network dynamics. We review the influences of cholinergic manipulations on behavioral performance in working memory, attention, episodic memory, and spatial memory tasks, the physiological effects of acetylcholine on neural and circuit dynamics, and the computational models that provide insight into the functional relationships between the physiology and behavior. Specifically, we discuss the important role of acetylcholine in governing mechanisms of active maintenance in working memory tasks and in regulating network dynamics important for effective processing of stimuli in attention and episodic memory tasks. We also propose that theta rhythm plays a crucial role as an intermediary between the physiological influences of acetylcholine and behavior in episodic and spatial memory tasks. We conclude with a synthesis of the existing modeling work and highlight future directions that are likely to be rewarding given the existing state of the literature for both empiricists and modelers.

Keywords: entorhinal cortex, spatial navigation, oscillatory interference, theta, memory, attention, acetylcholine, computational model

\section{INTRODUCTION}

Acetylcholine has a broad range of neuromodulatory influences on the cellular properties of hippocampal and cortical neurons and, as a result, on neural information processing important for behavior. Here we review experimental data on cholinergic modulation of neural networks in the context of different cognitive functions and describe computational models that connect the modulatory effects to each cognitive function. We begin with an overview of the role that computational models play for bridging the gaps in our understanding between physiological and behavioral influences of cholinergic modulation. After this, we review relevant anatomical pathways. We then address the role of acetylcholine in working memory, attention, episodic memory, and spatial memory in turn as understood from experimental data and computational modeling. Finally, we conclude with a synthesis of the unifying threads apparent across domains and discussion of directions of future research that are likely to be rewarding given existing empirical and modeling work.

\section{MODELING ADDRESSES QUESTIONS ABOUT CHOLINERGIC FUNCTION IN THE CORTEX}

Acetylcholine plays an essential role in cognitive function. At high doses, drugs such as scopolamine that block the effects of acetylcholine at muscarinic receptors cause a complete breakdown in cognitive function manifesting as delirium (Ostfeld and Aruguete, 1962; Crow and Grove-White, 1973). At lower doses, these drugs impair performance in cognitive tasks assessing memory function and attentional performance (Beatty et al., 1986). Similar to these robust behavioral effects, physiological data from intracellular recording of single neurons show robust and consistent effects of acetylcholine on the function of individual neurons. These effects include depolarization (Cole and Nicoll, 1984), reductions in spike frequency accommodation (Madison and Nicoll, 1984), enhancement of long-term potentiation (LTP) (Gil et al., 1997) and presynaptic inhibition of glutamatergic (Hasselmo and Bower, 1992; Hasselmo, 1999) and GABAergic synaptic transmission (for review, see Heys et al., 2012 in this issue).

Despite the striking behavioral effects of acetylcholine receptor blockade, and the robust physiological effects of acetylcholine on neurons in vitro, the link between these levels of analysis is not clear. In particular, few studies have addressed how the blockade of acetylcholine receptors influences the firing patterns of neurons in awake, behaving animals. In addition, despite the strong behavioral effects of systemic injections of pharmacological agents, the effects of selective lesions of acetylcholine neurons are not always consistent. In the review presented here, we will address the available data on effects of acetylcholine on firing patterns in awake, behaving animals, and also address potential factors influencing the nature of behavioral effects of cholinergic lesions. In particular, we will address network factors influencing behavioral effects including the role of theta rhythm oscillations, top-down feedback control of cholinergic modulation, and the role of novelty in behavioral effects. 
Computational modeling of cortical circuits provides a framework for linking the cellular effects of acetylcholine to the spiking activity of neurons in behaving animals and the role of acetylcholine in behavioral function. Therefore, we will frame our discussion in the context of computational models of neural circuits that have direct implications for understanding the link between the cellular influences of acetylcholine and cognitive performance (Hasselmo et al., 1992, 1995, 2002; Hasselmo and Schnell, 1994; Hasselmo, 1999; Menschik and Finkel, 1999; Norman et al., 2006; Burgess et al., 2007; Hasselmo, 2008). These models include analysis of cholinergic effects on circuit dynamics in the hippocampus (Hasselmo and Schnell, 1994; Hasselmo, 1999; Menschik and Finkel, 1999), models of the functional role of theta rhythm oscillations (Hasselmo et al., 2002; Norman et al., 2006) and models of grid cell firing in entorhinal cortex (Burgess et al., 2007; Hasselmo, 2008).

Discussion of these topics requires some review of previous data on the anatomy of cholinergic innervation of cortical structures, the modulatory influences on acetylcholine, and different techniques used to study the role of acetylcholine in behavior.

\section{ANATOMICAL OVERVIEW}

\section{Cholinergic projections}

Acetylcholine is released from neurons projecting to a broad range of cortical and subcortical sites. These projections can be split into two groups: the magnocellular basal forebrain cholinergic system and the brainstem cholinergic system (Mesulam et al., 1983a,b; Everitt and Robbins, 1997; Mike et al., 2000). As summarized in Figure 1, the basal forebrain cholinergic system includes cells located in the medial septal nucleus (MS), the vertical, and horizontal limbs of the diagonal band of Broca (DB), and the nucleus basalis magnocellularis (nBM; i.e., nucleus basalis of Meynert). These structures send cholinergic (as well as noncholinergic) projections to a broad range of sites in the neocortex as well as limbic cortices such as cingulate cortex, entorhinal cortex and hippocampus, and other structures including the basolateral amygdala and the olfactory bulb (Mesulam et al., 1983a). The entorhinal cortex receives some of the densest cholinergic innervation of cortical structures (Mesulam et al., 1983a). The cholinergic fibers in cortical structures have many axonal varicosities that are not associated with postsynaptic densities (Umbriaco et al., 1994, 1995), suggesting that acetylcholine influences neurons via diffuse extrasynaptic modulation termed volume transmission (Descarries et al., 1997). Therefore, the effects of acetylcholine in computational models are commonly implemented as uniform modulation of cellular parameters of depolarization and synaptic transmission throughout the local circuits of a model (Hasselmo et al., 1992, 1995; Hasselmo and Schnell, 1994).

The brainstem cholinergic system, which includes neurons located in the pedunculopontine tegmental nucleus (PPT) and laterodorsal pontine tegmentum (LDT) principally innervate the

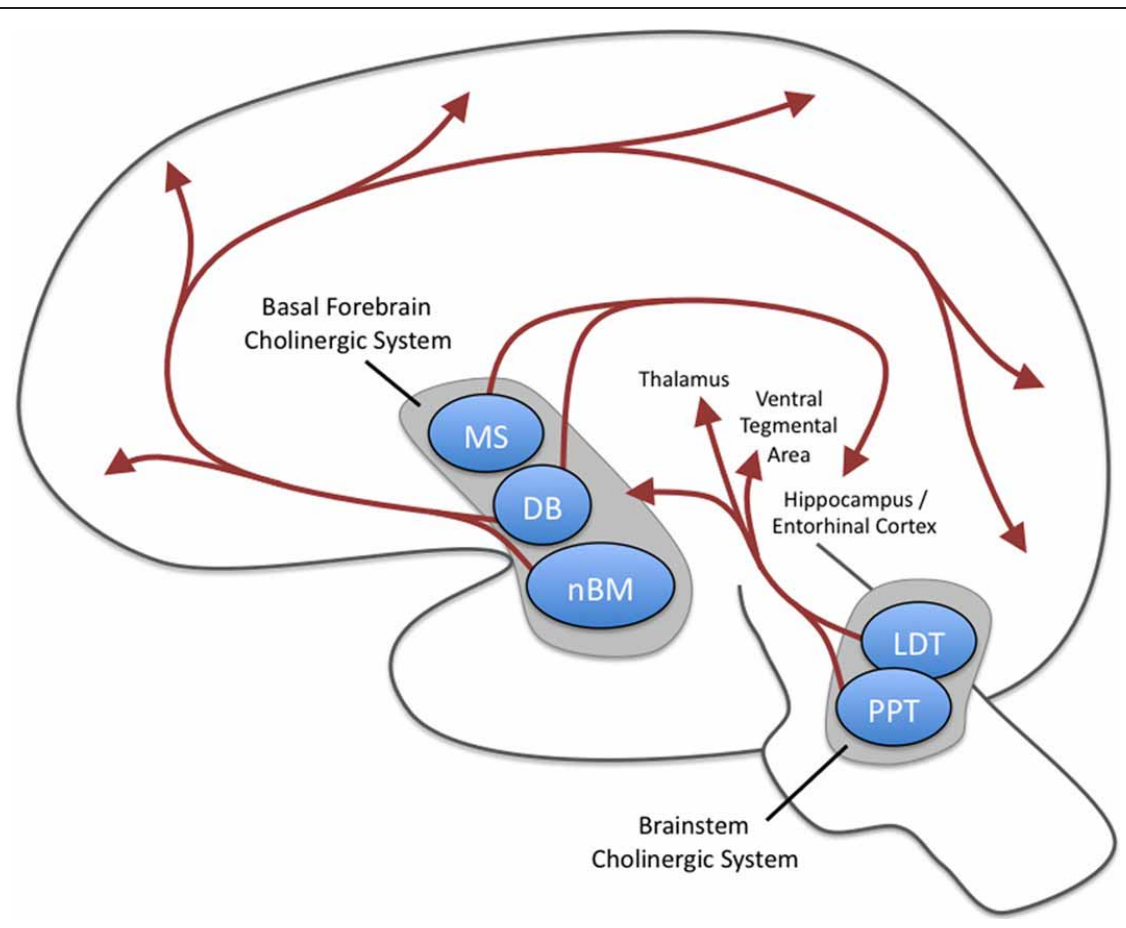

FIGURE 1 | Major cholinergic projections of the central nervous system. Two groups of projections exist: the magnocellular basal forebrain cholinergic system and the brainstem cholinergic system. The magnocellular basal forebrain cholinergic system includes the medial septal nucleus (MS), the vertical and horizontal limbs of the diagonal band of Broca (DB), and the nucleus basalis magnocellularis (nBM). The horizontal limb of the DB and
nBM has extensive diffuse projections to neocortex as well as projections to basolateral amygdala and olfactory bulb (these latter two are not shown here). The MS and vertical limb of the DB project to hippocampus and entorhinal cortices. The brainstem cholinergic system includes the pedunculopontine tegmental nucleus (PPT) and laterodorsal pontine tegmentum (LDT) and projects predominantly to the thalamus but also to the basal forebrain region. 
thalamus and basal ganglia but also innervates the basal forebrain and serves as a minor component of the cholinergic innervation of cortical structures (Mesulam et al., 1983a; Rye et al., 1987). Each of projections are particularly well positioned to have broad impacts on neural processing. For example, stimulation of the cholinergic projections into the ventral tegmental area (VTA) induces dopamine release-an effect that contributes to the addictive properties of smoking cigarettes (Pidoplichko et al., 2004). Mesulam and colleagues proposed the ch1-6 nomenclature to specifically refer to the distinct pathways as shown in Table 1.

\section{Projections into basal forebrain}

An important unanswered question concerns the mechanisms of regulation of acetylcholine levels within cortical circuits. Although rarely simulated explicitly in computational models of cholinergic function, such regulatory mechanisms play a critical role in shaping the cognitive influences of acetylcholine. Incorporation of these pathways into future modeling work would be fruitful, and, as such, we briefly review these connections here. Regulatory feedback originates from cortical structures and from bottom-up control of cholinergic neurons. In contrast to the broad range of targets of the cholinergic neuron projections, a comparatively restricted set of areas send excitatory or inhibitory feedback to the basal forebrain. Within the neocortex, glutamatergic feedback projections to the basal forebrain originate in the medial and ventral prefrontal and agranular insular cortices (Carnes et al., 1990; Záborsky et al., 1997).

Table 1 | Anatomical overview of cholinergic projections with corresponding Ch1-6 nomenclature.

\begin{tabular}{|c|c|c|c|}
\hline System & $\begin{array}{l}\text { Cholinergic } \\
\text { cell group }\end{array}$ & $\begin{array}{l}\text { Containing } \\
\text { nuclei }\end{array}$ & Target \\
\hline Basal forebrain & Ch1 & Medial septum & Hippocampus \\
\hline Basal forebrain & Ch2 & $\begin{array}{l}\text { Vertical limb of the } \\
\text { diagonal band of Broca }\end{array}$ & Hippocampus \\
\hline Basal forebrain & Ch3 & $\begin{array}{l}\text { Lateral part of horizontal } \\
\text { limb of the diagonal band } \\
\text { of Broca }\end{array}$ & Olfactory bulb \\
\hline Basal forebrain & Ch4 & $\begin{array}{l}\text { Nucleus basalis } \\
\text { magnocellularis (i.e., } \\
\text { nucleus basalis of } \\
\text { Meynert), Globus } \\
\text { pallidus, neurons lateral } \\
\text { to the vertical limb, and } \\
\text { neurons in the medial } \\
\text { part of the horizontal } \\
\text { limb of the diagonal band } \\
\text { of Broca }\end{array}$ & $\begin{array}{l}\text { Neocortex, } \\
\text { Basolateral } \\
\text { amygdala }\end{array}$ \\
\hline Brainstem & Ch5 & $\begin{array}{l}\text { Pedunculopontinus, } \\
\text { cuneiform, parabrachial } \\
\text { area }\end{array}$ & $\begin{array}{l}\text { Thalamus, } \\
\text { Basal ganglia }\end{array}$ \\
\hline Brainstem & Ch6 & $\begin{array}{l}\text { Lateral tegmental } \\
\text { nucleus }\end{array}$ & $\begin{array}{l}\text { Thalamus, } \\
\text { Basal ganglia }\end{array}$ \\
\hline
\end{tabular}

Stimulation of the hippocampus causes reductions in medial septum activity (McLennan and Miller, 1974a,b) that may arise from weak GABAergic projections from the hippocampus to the medial septum (Toth et al., 1993), or from connections via a circuit that includes anterior thalamus. Additional regulatory feedback comes from the GABAergic projections from the nucleus accumbens (Mogenson et al., 1983; Záborsky and Cullinan, 1992) as well as glutamatergic projections from the amygdaloid complex (Grove, 1988). Finally, the ascending reticular activating system, including the the pedunculopontine and laterodorsal nucleus, median raphe, and VTA, as well as the hypothalamus provide a wide range of neuromodulatory influences on cholinergic output of the basal forebrain including noradrenergic, serotonergic, and cholinergic input (Jones and Cuello, 1989). While the specific modulatory influences of each of the reciprocal projections is beyond the scope of this review (for a related review, see Fadel, 2011), it is worth highlighting that the anatomical regions from which these projections originate are frequently attributed with functions relevant to the regulation of the quality of information processing in the brain.

\section{Cholinergic receptor subtypes}

There are two general classes of acetylcholine receptors that can be dissociated by their binding affinity for muscarine and nicotine. At present, computational models of cholinergic function do not usually focus on dissociating the contribution of each of these receptor types. However, each has distinct properties that would have differential functional influences on cognition. The development of pharmacological therapies requires an understanding of the relative contributions of each receptor subtype for cognitive function. Thus, with the goal of drawing attention to the differential contributions of these receptor subtypes in future modeling work we have included an introduction to these receptor subtypes here and describe relevant observations regarding the contributions of each for the domains of cognition reviewed.

Receptors that are activated by muscarine (but not nicotine) are referred to as muscarinic cholinergic receptors and are g-protein coupled metabotropic receptors. Within the central nervous system there are five subtypes of muscarinic receptor that are differentiable via amino acid structure and immunohistochemistry: the M1 receptor is located predominantly at the post-synaptic sites (and is functionally related to the M3 and M5 receptors). The M1 receptor mediates post-synaptic effects of the activation of muscarinic receptors, including depolarization and suppression of spike-frequency accommodation (Dasari and Gulledge, 2011). M2 receptors are located at both pre- and post-synaptic sites and are functionally related to the M4 receptor (Mrzljak et al., 1993). The cholinergic modulation of glutamatergic synaptic transmission via activation of muscarinic receptors on glutamatergic terminals appears to involve the M4 subtype of receptor (Shirey et al., 2008; Dasari and Gulledge, 2011).

Ionotropic, cholinergic receptors that are activated by nicotine but not muscarine are designated as nicotinic receptors (nAChRs). In the brain, they exist as either heteropentamers of alpha and beta subunits or as homopentamers of alpha7 subunits. The diverse range of receptor properties, as well as their temporal and spatial specifity of expression, has a huge range of 
effects on the function of the brain. nAChRs have been found to be essential for development (Bear and Singer, 1986; Imamura and Kasamatsu, 1991; Hensch, 2004), regulation of cell survival and death (Treinin and Chalfie, 1995; Labarca et al., 2001; Hruska and Nishi, 2007; Hruska et al., 2009; Barbagallo et al., 2010), plasticity (Lagostena et al., 2008; Tu et al., 2009; West et al., 2010), and excitability (Albuquerque et al., 2009; Tu et al., 2009; Penton et al., 2011; Ondrejcak et al., 2012).

As an example, within the hippocampus, nAChRs are expressed primarily in the interneurons where they likely play a role in gating communication (Albuquerque et al., 2009). Alpha4beta2 (type I) receptors are sensitive to low concentrations of Ach $(0.1-1 \mu \mathrm{M})$ (Miwa et al., 2011), and have been described on the soma and dendrites of CA1 interneurons of mice (Alkondon et al., 1997; McQuiston and Madison, 1999; Mike et al., 2000; Sudweeks and Yakel, 2000), likely coinciding with chronic activation by basal levels of Ach (Albuquerque et al., 2009). Alpha4beta2 (type II) receptors are less sensitive than alpha4beta2 (type I) receptors (Miwa et al., 2011), and have been identified on the axonal segments of CA1 interneurons, where their activation by low concentrations of ACh can induce release of GABA without triggering an action potential (Alkondon et al., 1999). Alpha3beta3 beta2 receptors can be found on the axons of pyramidal associated interneurons (Albuquerque et al., 2009). Alpha7 nAChRs display much faster dynamics, a high calcium permeability, and activated by the ACh precursor choline (Albuquerque et al., 2009). Alpha7 receptors are found on the somata (Mike et al., 2000) and dendrites (Xu et al., 2006) of hippocampal neurons where they can regulate calcium responses, as well as on the axon terminal where they enhance transmitter release (Gray et al., 1996).

\section{ACETYLCHOLINE AND COGNITIVE FUNCTION}

Acetylcholine plays an important role in a range of cognitive domains: across empirical methods, working memory, attention, episodic memory encoding, and spatial memory processing are repeatedly found to depend upon acetylcholine for normal function. For each of these domains, a great deal of empirical evidence exists documenting this dependency. Similarly, a great deal is known regarding the physiological influences of acetylcholine on cellular or network dynamics. Our goal in the following section is to review how computational models have linked these seemingly disparate bodies of knowledge. Toward this end, we will discuss each cognitive domain in turn. For each domain, we first review evidence that acetylcholine is required for that type of cognition. We then review the physiological influences of acetylcholine that are likely to subserve that cognitive function, as suggested by the existing computational models. Finally, we describe the modeling work that links the physiology to the cognitive function with a specific focus on the implications and predictions that were born out of the relevant simulations.

\section{WORKING MEMORY}

Working memory provides a temporary store for information used during decision-making (Baddeley, 2000; Baddeley and Wilson, 2002; Hasselmo and Stern, 2006). Many animal studies have indicated that working memory networks are selectively active for familiar and novel stimuli. Familiar stimuli activate the prefrontal cortex (PFC) and parietal cortex of animals performing tasks involving delayed match to sample (DMS) (Fuster, 1973), cued-choice behavior (Fujisawa et al., 2008), object recognition (Asaad et al., 1998), and object localization (Monosov et al., 2010). The parahippocampal cortex and hippocampus, on the other hand, preferentially act as a working memory buffer during novel stimulus presentation. Unit recordings from rats (Young et al., 1997) and primates (Suzuki et al., 1997) and functional magnetic resonance imaging (fMRI) in humans (Schon et al., 2004, 2008) all show elevated activity in parahippocampal regions correlated with active maintenance in working memory tasks, with studies showing relatively higher activity for novel stimuli (Stern et al., 2001).

Of note, lesions of the inferior prefrontal convexity impair performance on DMS tasks with small sets of stimuli where the small size of the set makes each stimulus more familiar (Passingham, 1975; Bachevalier and Mishkin, 1986). Contrasting perirhinal and prefrontal lesions in rats, Otto and Eichenbaum (1992) showed that perirhinal lesions impaired performance on both an 8- and 16-set odor stimuli in a delayed non-match to sample study in rats. In contrast, prefrontal lesions affected the 8-set odor stimuli response, but did not impair performance for the larger stimulus set. These studies suggest that although the PFC is active for novel stimuli (or large stimuli sets), lesions of the PFC significantly disrupt working memory for familiar stimuli (or small stimuli sets) in contrast to lesions of parahippocampal cortices that impair memory for trial-unique stimuli (Gaffan and Murray, 1992; ZolaMorgan and Squire, 1993) and not familiar stimuli (Corkin, 1984; Otto and Eichenbaum, 1992; Eacott et al., 1994).

\section{Cholinergic effects on working memory tasks}

In both PFC and parahippocampus, depletion of cholinergic inputs disrupts performance of working memory systems. Croxson et al. (2011) has shown a significant disruption in primate spatial working memory following cholinergic-depletion of the PFC induced by basal forebrain lesions. Further, local infusions of scopolamine into the perirhinal cortex in rats was shown to slow the acquisition of working memory dependent (i.e., trace) fear conditioning task (Bang and Brown, 2009). Such impairments have been found to vary in a dose-dependent fashion with infusions of the M1-antagonist Pirenzepine (Esclassan et al., 2009; see also Ohno et al., 1994). Similar results have also been observed in humans following systemic injections of scopolamine in DMS tasks (Robbins et al., 1997; Koller et al., 2003) and visuospatial tasks (Thomas et al., 2008). The latter study showed impairments with scopolamine injections that were rescued by administration of donepezil, a cholinesterase inhibitor that could also improve performance from baseline in naïve patients (Thomas et al., 2008), corroborating similar rescue studies in rodents (Friedman, 2004; Padlubnaya et al., 2005). fMRI studies in humans also show reduced correlations between delay period activity and subsequent memory after scopolamine administration (Schon et al., 2005). In a study comparing the effect of systemic injections of scopolamine and the nicotinic receptor antagonist mecamylamine in humans, patients were impaired on an $n$-back memory test with scopolamine 
alone, and were synergistically impaired with scopolamine and mecamlyamine (Green et al., 2005). Muscarinic blockade, however, does not impair performance on short-term memory tasks such as digit span (Broks et al., 1988) suggesting the familiar stimuli used in these paradigms may have already sufficiently strengthened synaptic connections, thereby reducing the need for cholinergic input to modulate mechanisms of active maintenance. This suggests that the cholinergic modulation of working memory might be more important for novel than for familiar stimuli.

\section{Persistent spiking in the entorhinal cortex}

Intracellular recording from in vitro slice preparations of rat medial entorhinal cortex (EC) suggest a mechanism for the working memory of novel stimuli that is modulated by acetylcholine. Single neurons in medial EC typically spike in an unsustained fashion after a single depolarizing current. However, bath application of cholinergic agonists like carbachol in the presence of a depolarizing current injection produces persistent spiking that continues after the termination of the depolarizing stimulus (Klink and Alonso, 1997; Egorov et al., 2002; Yoshida et al., 2008). One possible cellular mechanism for this sustained activity suggests that cortical glutamatergic synaptic input, released after stimulus presentation during an attention-driven task, triggers calcium-induced spiking in medial EC neurons while also providing feedback on cholinergic axons. Acetylcholine activation of muscarinic receptors activates a calcium-sensitive non-specific cation current $\left(\mathrm{I}_{\mathrm{CAN}}\right)$ on medial EC neurons allowing further depolarization from calcium-influx resulting in self-sustained persistent spiking (see Hasselmo and Stern, 2006 or Hasselmo and Sarter, 2011 for review).

\section{Acetylcholine may support active maintenance through sustained activation}

Several computational models have shown how these intrinsic mechanisms for persistent spiking activity could provide a mechanism for maintenance of working memory for novel inputs during performance of DMS tasks and encoding of long-term memories. Fransén et al. (2002) simulated biophysical networks of the EC with a predominant muscarinic-activated non-specific calcium current, $\mathrm{I}_{\mathrm{NCM}}$ (now known as $\mathrm{I}_{\mathrm{CAN}}$ ). The presence of $\mathrm{I}_{\mathrm{NCM}}$ allowed simulated pyramidal cells to sustain spiking activity after transient depolarization even after removing a persistent sodium current $(\mathrm{NaP})$, potassium $\left(K_{M}\right)$ current, or a combination of $\mathrm{NaP}, K_{M}$, afterhyperpolarization potassium current $\left(K_{A H P}\right)$, and internal calcium. The removal of currents involved in action potential generation and the $\mathrm{I}_{\mathrm{NCM}}$ degraded any sustained spiking during the delayed working memory behavior correlates tested.

These intrinsic cellular properties strongly suggest cholinergic gating of persistent spiking onset actively switch neurons into maintenance modes that can represent new information. In vivo studies have shown elevations in entorhinal and hippocampal activity from rodents (Young et al., 1997), monkeys (Suzuki et al., 1997), and humans (Stern et al., 2001; Schon et al., 2004, 2005) which could represent persistent spiking selectively gated by acetylcholine to specific stimuli. Such selective gating is necessary to maintain information even in the presence of distractor stimuli (Suzuki et al., 1997). Subjects administered scopolamine are impaired in tasks with distractor stimuli such as the n-back task (Green et al., 2005) further suggesting that cholinergic modulation gates the role of persistent activity.

More work is needed, however, to fully understand the gating mechanism gleaned from in vitro and computational modeling of persistent spiking. A predilection for novel environments (Acquas et al., 1996; Thiel et al., 1998) and objects (Degroot et al., 2005; Stanley et al., 2012) to increase rat hippocampal acetylcholine levels also argues toward cholinergic gating of preferential signal throughput carrying new information. Lack of cholinergic modulation via deafferentation of the rat EC spares working memory for familiar odor stimuli, but impairs working memory of novel stimuli, in a delayed non-match to sample task (McGaughy et al., 2005). Similar lesions also reduce rat exploration of novel objects (Winters and Bussey, 2005) and impair formation of novel association for location and context (Easton et al., 2010). Further study is also necessary to see neurotransmitter dynamics over extended learning periods. In a recent study, Gupta et al. (2012) looked for a cue-elicited increase in medial EC unit spiking activity of overtrained rats during the delay period of an appetitive, delayed spatial response task. Medial EC neuron firing rate surprisingly dropped during the delay period. If this drop in firing rate had been cholinergic modulated, at what point in the animal's learning did acetylcholine's role change? Shedding light on how and when persistent neuronal activity is regulated via acetylcholine will unlock key pharmacological insights into diseased states impairing working memory.

\section{ATTENTION}

The ability to effectively process stimuli depends upon the healthy function of the cholinergic system (for reviews, see Sarter et al., 2005; Hasselmo and Sarter, 2011; Klinkenberg et al., 2011). Here, we conceptualize effective processing as the ability of neural tissue to adequately update its pattern of activation in response to external stimuli or events to meet task demands and to resolve ambiguity. Under this conceptualization, we assume that attention is the active process under which the brain ensures a given signal is effectively processed. There is a clear correspondence between cholinergic function and attention, as shown through behavior that is readily linked to physiological observations through modeling. In this section, two such models are described following a brief review of relevant behavioral and physiological data.

\section{Cholinergic modulation supports attentional processing}

Studies of people who smoke have led to the understanding that the selective cholinergic agonist nicotine facilitates attentional processing (for a review, see Mansvelder et al., 2006). Supporting evidence includes demonstrations that smokers deprived of nicotine are impaired on attention demanding tasks and that nicotine administration can return their performance to baseline levels. In non-smokers, nicotine has been shown to boost visual attention performance (Ernst et al., 2001).

Experiments monitoring acetylcholine release through microdialysis in freely moving rats have observed relative increases in acetylcholine associated with attention-like behavior (Moore 
et al., 1992; Inglis et al., 1994; Sarter et al., 1996; Himmelheber et al., 2000). Much of what has been learned regarding the relationship between acetylcholine release and attention has been derived from the sustained attention task (the SAT) developed by Sarter and colleagues. In this task, rats are required to continuously attend to a house light-pressing a lever whenever the light is turned on and withholding lever presses when the light is extinguished. Importantly, the stimuli appear at irregular intervals requiring that the animal sustain its attention to avoid missing stimuli. In this task, Arnold et al. (2002) found a peak efflux of nearly $140 \%$ of baseline levels as animals performed the SAT but found an efflux of about $50 \%$ as animals performed the matched control tasks that did not tax attention but were matched for factors such as novelty and movement (see also Himmelheber et al., 1997). Interestingly, acetylcholine efflux demonstrated a higher correspondence to attentional demand than it did to task performance in this task (Kozak et al., 2006) and in other attention demanding tasks (e.g., the five-choice serial reaction time task, Passetti et al., 2000; Dalley et al., 2001). With this observation in mind, Sarter and colleagues have argued that the dynamics of acetylcholine release reflects attentional effort (for relevant reviews, see Sarter et al., 2005, 2006).

Methodological advances, making it possible to detect changes in choline levels with sub-second temporal resolution using amperometry (Parikh et al., 2004), have brought further insight into the anatomical specificity of cholinergic release. Parikh et al. (2007) found that large changes in acetylcholine levels occurs at very fast $(\sim 1-2 \mathrm{~s})$ timescales during cue detection in rats and smaller changes in baseline acetylcholine levels occur over slower timescales $(\sim$ minutes $)$ between trials. Further, they found significantly elevated phasic acetylcholine release in medial PFC, but not in motor cortex when animals detected a cue in the SAT, despite both receiving cholinergic projections. Errors in cue detection did not elicit a concomitant increase in synaptic acetylcholine, and subsequent cholinergic deafferentation of the medial PFC led to significant impairments in cue detection. In contrast, operant cue stimuli, assessing habituated responses, do not appear to be subserved by acetylcholine (Himmelheber et al., 1997).

Cholinergic depletion studies further underscore the importance of acetylcholine for attentional processing. Injections of 192 IgG-Saporin into a cholinergic nucleus causes selective cell death of the cholinergic cells (Wiley et al., 1991). Using this approach, McGaughy et al. (1996) found that selective cholinergic deafferentation of cortex, by infusing 192 IgG-saporin into the nucleus basalis/substantia innominata of the basal forebrain, of rats previously trained on the SAT elicited selective deficits in stimulus detection. Further, they were unable to restore preoperative performance after extensive additional training but found that the final performance across animals correlated with the residual integrity of the cholinergic pathways. Consistent with the observed relationship between cholinergic efflux and attentional demand (e.g., Arnold et al., 2002), the behavioral consequence of corticopetal cholinergic projections lesions varies as a function of the attentional demands of the task employed. For example, Turchi and Sarter (1997) found that such lesions of the corticopetal cholinergic projections were particularly detrimental to performance on a more difficult crossmodal divided attention variant of the SAT (i.e., response cues could be presented as either visual or auditory stimuli) relative to performance on a unimodal form of the SAT. It is likely that the attention benefiting properties of acetylcholine occur in the PFC: targeted lesions of cholinergic projections to the PFC in rats increased sensitivity to distractor cues and led to increased impulsive responses during SATs (Dalley et al., 2004; Newman and McGaughy, 2008).

Mutant mice, in which $\alpha 7$ nicotinic receptors have been removed, show effect that suggest that the $\alpha 7$ receptors, at least, play an important role in attentional processing. $\alpha 7$ receptor knockout mice take longer to reach asymptotic performance on attention demanding tasks and exhibit greater numbers of errors than do wild-type mice (Young et al., 2004).

\section{Acetylcholine supports processing of extrinsic signals}

Given the clear importance for acetylcholine in attentional processing, what are the relevant physiological processes? Fortunately, physioglogical studies of cholinergic function, particularly in cortical tissue, tell a relatively coherent story: acetylcholine potentiates afferent projections while suppressing intrinsic projections, thereby allowing for greater processing of extrinsic stimuli (for a review, see Hasselmo, 1999; Hasselmo and Sarter, 2011). Early unit recording studies in anesthetized animals showed enhanced spiking responses of cortical neurons during acetylcholine application (Krnjevic and Phillis, 1963). Similarly, the amplitude of evoked potentials in somatosensory cortex following somatic stimulation was amplified following basal forebrain stimulation (Tremblay et al., 1990). More recent studies in awake, behaving animals allow analysis of the modification of functional properties. The local application of acetylcholine enhances the response of primary visual cortex neurons to visual input (Sato et al., 1987; Disney et al., 2007) and enhances the direction selectivity of individual neurons (Murphy and Sillito, 1991).

Concomitant with enhanced afferent input, high acetylcholine levels also suppress recurrent connections at glutamatergic feedback synapses as observed in piriform cortex and region CA3 of the hippocampus (Hasselmo and Bower, 1992, 1993; Hasselmo et al., 1995; Linster et al., 1999; Kremin and Hasselmo, 2007). For example, Linster et al. (1999) found that stimulation of the cholinergic projection to piriform (olfactory) cortex in rodents increases the amplitude of the evoked response resulting from stimulation of the lateral olfactory tract and decreased the amplitude of the evoked response resulting from stimulation of the posterior piriform cortex. Similarly, slice preparations have shown that acetylcholine causes selective presynaptic inhibition of glutamatergic synaptic transmission at feedback synapses, but not at afferent synapses from the lateral olfactory tract (Hasselmo and Bower, 1992).

In visual cortex, acetylcholine sharpens visual receptive field tuning through a reduction in spatial integration (Roberts et al., 2005; Roberts and Thiele, 2008; Silver et al., 2008). Specifically, Roberts et al. (2005) showed that local iontophoresis of acetylcholine into the visual cortex reduces the preferred length of visual stimuli for cortical neurons. This is consistent with the idea that cholinergic modulation reduces the response of neurons to input from more distant points on the retinotopic 
map in primary visual cortex, potentially due to presynaptic inhibition of intracortical excitatory synapses that reduces the excitatory spread of activity (Disney et al., 2006; Disney and Aoki, 2008). Consistent with this, administration of acetylcholinesterase blockers to human subjects reduces the retinotopic spread of fMRI activity in response to visual stimuli (Silver et al., 2008).

Consistent with the behavioral data that draw attention to nicotinic receptors playing a particularly important role in attentional processing, physiological studies show that amplification of afferent signals likely depends on nicotinic receptors. High cholinergic levels cause direct nicotinic enhancement of thalamocortical afferent synapses (Gil et al., 1997; Disney et al., 2007) and potentiate synapses in the dentate gyrus and region CA1 of the hippocampus (Gray et al., 1996; Giocomo and Hasselmo, 2005). Conversely, suppression of the intrinsic synapses likely depends on muscarinic receptors. Muscarinic receptor blockade has effects on neuronal responses that resemble reductions of attentional response to afferent input in behavior. In the primary visual cortex, blockade of muscarinic but not nicotinic receptors impairs the attentional modulation of V1 neurons (Herrero et al., 2008; Deco and Thiele, 2009).

\section{Acetylcholine tunes network dynamics for more effective processing}

Computational models bolster the understanding that the physiological influences of acetylcholine support selective processing of extrinsic stimuli, thereby leading to greater signal to noise quality of perceptual processing. Simulations have shown that the ability to dynamically switch between processing extrinsic versus intrinsic signals improves the quality of encoding of stimuli (e.g., Hasselmo et al., 1992; Linster and Hasselmo, 1997). For example, Hasselmo et al. (1992) simulated the findings of Hasselmo and Bower (1992), showing that application of cholinergic agonist suppresses transmission at intrinsic synapses, using a neural network model of piriform cortex. The model consisted of a single layer of rate coded point neurons receiving feed forward connections, representing afferent projections carrying sensory information, and recurrent feedback connections, representing intrinsic projections carrying information about the activation state of the neural network. The strength of the connection between the model neurons and the recurrent connections were tuned via Hebbian synaptic modification during stimulus presentation. Without cholinergic modulation, the input from the recurrent feedback connections interfered with accurate encoding of stimuli if the activity patterns were similar to previous inputs. However, cholinergic presynaptic inhibition of these recurrent feedback connections during the presentation of new stimuli, simulating the role of acetylcholine in cortical processing, minimized this interference.

The suggestion that acetylcholine serves to improve the signalto-noise of neural information processing raises the question of why the system would not be tuned for optimal information processing at all time. There are two reasons why the ability to gate external information processing may be advantageous. The first is that there are times when the ability to generally tune out the external world is beneficial (e.g., while consolidating memories, as discussed in the next section). The second reason is that the ability to selectively gate information processing may allow for flexible modification of behavior to the same environmental stimuli by regulating which brain areas are used in processing (see Gold, 2003 for review of related evidence).

Another view of the role of acetylcholine in attentional processing, described by Yu and Dayan (2005), suggests that acetylcholine selectively gates top-down versus bottom-up processing. This view is in contrast to the previously described model that acetylcholine boosts the signal-to-noise quality of neural processing in that it explicitly assumes that background processing is not only retrieval, but instead can serve as a top-down source of contextual disambiguation. Under this conceptualization, perceptual uncertainty can be offset by selectively gating in top-down biases in neural processing through cholinergic regulation. Such a mechanism allows for effective perceptual inference under ambiguous conditions (Yu and Dayan, 2002). Such a view is well supported by the empirical literature (see Yu and Dayan, 2005, for a relevant review) and merits additional direct investigation both in animal models and through additional simulations.

\section{EPISODIC MEMORY}

The pivotal role that acetylcholine plays for cue processing directly predicts the importance of acetylcholine for encoding new memories. The fidelity of a memory is fundamentally limited by how effectively the relevant information was processed at encoding. Indeed, it has been shown that administering scopolamine to subjects prior to encoding a list of words produces drastic reductions in accuracy of subsequent free recall of the words, but that administering after encoding does not impair subsequent free recall (Ghoneim and Mewaldt, 1975; Petersen, 1977). Yet, a surprising number of studies using animal models have reported spared memory function following disruption of the basal forebrain cholinergic system (e.g., Voytko et al., 1994). Sarter and colleagues (2003) point out, however, that the animal subjects of these experiments are typically over trained and are highly familiar with the stimuli and task demands. As such, they suggest that little attentional effort is required to perform these tasks. Consistent with this argument, memory deficits were observed, for example, when novel stimuli were used in a recognition memory task following local infusions of scopolamine into perirhinal cortex in monkeys (Tang et al., 1997) and in recognition studies of novel objects or delayed non-match to sample with novel odors in rats (McGaughy et al., 2005; Winters and Bussey, 2005). Taken together, these data suggest that acetylcholine is specifically beneficial in circumstances when the neural attractors do not yet exist for representing the task stimuli in a manner adequate for good behavioral performance.

Behavioral studies highlight the likely role that nicotinic cholinergic receptors play in supporting the formation of episodic memories. Studies in healthy humans have found improved performance on memory tasks following the administration of nicotine or selective nicotinic agonists (Howe and Price, 2001; Kitagawa et al., 2003). In rodents, nicotine has been shown to boost memory performance in a passive avoidance task (Faiman et al., 1991). Mutant mice, missing the gene for the beta 2 subunit of nicotinic receptors were not found to benefit from nicotine on 
the same task (Picciotto et al., 1995). Across studies performed in animals, both the alph4beta2 and the alpha7 nicotinic receptors have been found to support performance on memory tests (Bohme et al., 2004; Chan et al., 2007; Pichat et al., 2007).

Acetylcholine likely supports the creation of novel attractors in cortical circuits in two ways. The first, as described in the previous section, is to increase the extent that afferent signals influence cortical activity while simultaneously decreasing the extent that intrinsic signals influence activity. The second way, which will be described in greater detail in this section, is to enhance physiological phenomena that support the encoding of memories. Hasselmo (1999, 2006) reviews a number of such phenomena; here, we discuss two that are particularly relevant for existing computational models: (1) lowering the threshold for the induction of LTP, and (2) boosting the amplitude of theta oscillations. Each are described below.

\section{Acetylcholine enhances LTP}

Neurophysiological studies demonstrate that acetylcholine modulates synaptic plasticity. For example, in rats, LTP induced by tetanic stimulation of synapses on CA1 basal dendrites was shown to be greatest when the stimulation was delivered during walking relative to during awake-immobility, slow wave sleep or rapid eye movement sleep (Leung et al., 2003). This effect was blocked by either scopolamine or by IgG-saporin lesions of the medial septal cholinergic projections into the hippocampus, suggesting that the effect was due to the increased release of acetylcholine that occurs during walking (Marrosu et al., 1995; see also Ovsepian et al., 2004).

In vitro studies similarly show that cholinergic agonists, including selective agonists for both muscarinic and nicotinic receptors, lower the threshold for LTP induction in region CA1 of the hippocampus (Blitzer et al., 1990; Huerta and Lisman, 1993, 1995; Adams et al., 2004), in the EC (Yun et al., 2000; Cheong et al., 2001), and in piriform cortex (Patil et al., 1998). For example, a single burst of high frequency stimulation, although typically ineffective at inducing synaptic plasticity, is sufficient to induce LTP in hippocampal CA1 neurons following bath application of carbachol (Huerta and Lisman, 1993). These effects of cholinergic modulation are illustrated in Figure 2.
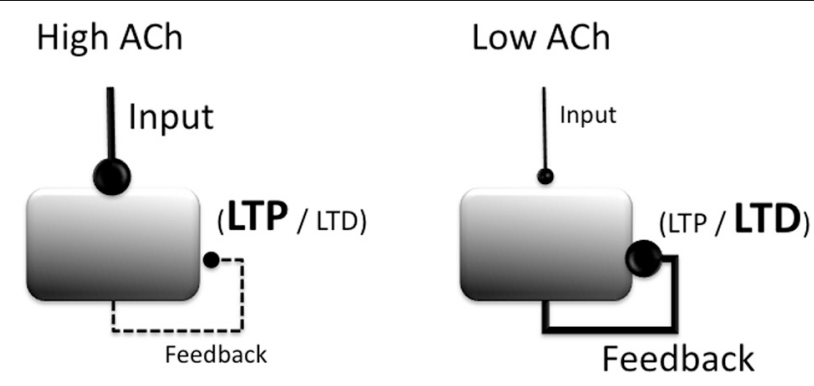

FIGURE 2 | Summary of modulatory effects of acetylcholine (ACh) on cortical circuit dynamics. Increased ACh (left) boosts the processing of extrinsic afferent projections, suppresses intrinsic projections, and lowers the threshold for the induction of long-term potentiation (LTP). Reduced ACh boosts processing of intrinsic projections, raises the threshold for the induction of LTP and increases the likelihood that LTD is induced.
Nicotinic receptors are well positioned to alter the dynamics of plasticity induction. Application of nicotine to hippocampal slices facilitates the induction of LTP (e.g., Fujii et al., 1999). Independent pharmacological manipulation of the alpha4beta2 and alpha7 receptors have revealed that both are capable of inducing LTP but that the alpha7 receptors, in particular, induce a more stable form of LTP (Kroker et al., 2011). Notably, however, nicotinic receptors can also inhibit the induction of LTP by exciting local inhibitory interneurons (e.g., Ji et al., 2001) thereby inducing a temporal and spatial sensitivity to the influences of cholinergic modulation.

\section{Theta rhythms are important for learning}

The amplitude and occurrence of hippocampal theta oscillations are intimately tied to acetylcholine further motivating the idea that acetylcholine plays an important role for memory encoding. Theta, a prominent oscillatory rhythm that is clearly observed in local field potentials of the hippocampus of rats (e.g., Vanderwolf, 1969; Buzsaki et al., 1983; Buzsaki, 2002) and humans (Kahana et al., 1999) appears when stimuli are presented during memory tests in humans (Raghavachari et al., 2001). The amplitude of theta is predictive of improved memory encoding. In humans, for example, Sederberg et al. (2003) found that the amplitude of intracranially recorded theta oscillations during encoding in a free recall task was significantly greater for subsequently recalled words than for forgotten words. Similarly, rabbits reach a criterion performance level in an eye-blink conditioning protocol in fewer trials when trial presentation was restricted to epochs of elevated hippocampal theta power than when trial presentation was restricted to epochs of low theta power (Griffin et al., 2004; see also Asaka et al., 2000, 2002).

The link between theta and learning is extended by an interesting set of findings demonstrating a dependence between theta phase and the induction of LTP. In short, LTP is preferentially induced during the peak of theta in the local field potential whereas LTD is preferentially induced during the trough of theta in the local field potential. This was first discovered by Huerta and Lisman (1995) when they found that a single tetanic stimulation burst was sufficient to induce LTP in a hippocampal slice when the stimulation was delivered selectively at the peak of theta oscillations generated following the bath application of carbachol. Further, they found that co-application of a muscarinic antagonist blocks this induction of LTP. This phase specific induction of plasticity has since been replicated in vivo in anaesthetized animals (Hölscher et al., 1997) and in awake behaving animals (Hyman et al., 2003).

\section{Acetylcholine modulates theta}

Theta rhythm is modulated by cholinergic and GABAergic inputs from the medial septum via the fornix (Stewart and Fox, 1990; Vertes and Kocsis, 1997; Buzsaki, 2002), and increases in acetylcholine are associated with theta oscillations (Monmaur et al., 1997; Zhang et al., 2010). However, hippocampal theta may depend on two separate frequency components, namely a cholinergic-independent, movement-related theta rhythm at 8-9 Hz (type 1) and a lower frequency $6-7 \mathrm{~Hz}$ cholinergicdependent component (type 2) (Kramis et al., 1975; Jeewajee 
et al., 2008). In vivo studies of rats have shown that infusions of cholinergic agonists into the medial septum increase hippocampal theta power whereas infusions of cholinergic antagonists reduce hippocampal theta power (for a detailed review, see Vinogradova, 1995). Cholinergic inputs from the basal forebrain are important for this oscillatory activity; in rats, lesioning the septal nuclei substantially reduces hippocampal theta (Green and Arduini, 1954) and selective lesions of the septal cholinergic neurons greatly decreases the magnitude of theta (Lee et al., 1994).

\section{Models show how theta may support learning}

Computational models show that the ability of acetylcholine to simultaneously modulate the plasticity induction threshold and the relative strength of intrinsic and extrinsic projections has important functional effects. For example, Linster and Hasselmo (1997) found that such modulation had a substantial impact on the ability of a neural network model of piriform cortex to perform pattern separation among similar odor stimuli. Specifically, by blocking the retrieval of previously stored representations (through suppression of transmission at intrinsic synapses), the state of the network during presentation of novel stimuli was less biased toward states that had been previously potentiated.

A related model, described by Hasselmo (1994), underscores the importance of blocking the retrieval of prior associations during novel encoding. This model demonstrates that a break down in the separation between retrieval and encoding can lead to the excessive strengthening of synapses. Across a range of simulations, it was shown that if left unchecked, such runaway growth of synapses can manifest in symptoms similar to those seen in Alzheimer's disease including neural degeneration, retrograde amnesia, dementia, and eventually anterograde amnesia (see also Hasselmo, 1997).

Along these lines, a model proposed by Hasselmo et al. (2002) suggests that encoding and retrieval were kept distinct by occurring at opposite phases of the theta rhythm in the hippocampus. In this model, network parameters such as the strength of afferent projections into area CA1 from EC and the threshold for modification of synapses from area CA3 into CA1 are dynamically modulated on each theta cycle. Specifically, at the trough of theta (recorded at the fissure or at the peak of theta recorded at the CA1 cell layer) the strength of EC projections into CA1 are strongest, and the threshold for LTP induction at synapses from CA3 is lowest, allowing for new encoding. Conversely, at the peak of theta (at the fissure, trough at CA1 cell layer) the strength of CA3 projections into CA1 are strongest and depotentiation of the synapses of these projections onto CA1 neurons occurs most easily, providing for retrieval (and forgetting) of previously learned memories. As such, theta may serve to cycle between a network-tuning regime optimized for encoding new memories and a tuning regime to allow for the expression (and extinction) of previous learning.

A complementary model of the role of theta in memory encoding suggests that theta boosts the signal-to-noise quality, not just of neural information processing, but of memory encoding as well (Norman et al., 2005, 2006). As summarized in Figure 3, Norman and colleagues show how inhibitory oscillations, such as theta, can parse neuron-by-neuron differences in sub-threshold depolarization into a phase code. Specifically, only highly excited (i.e., most depolarized) cells activate during the highest inhibition phase while less excited cells activate during the lower inhibition phase. By separating the activation of neurons in time based on the amount of excitation they receive, the oscillation then allows for differential treatment of strongly excited neurons and moderately excited neurons. They argue that the moderately excited neurons interfere with the effective processing of the strongly excited neurons, and as such, serve as a source of noise. They then suggest that phase-specific synaptic induction of LTP and LTD (as described, for example, by Huerta and Lisman, 1995)

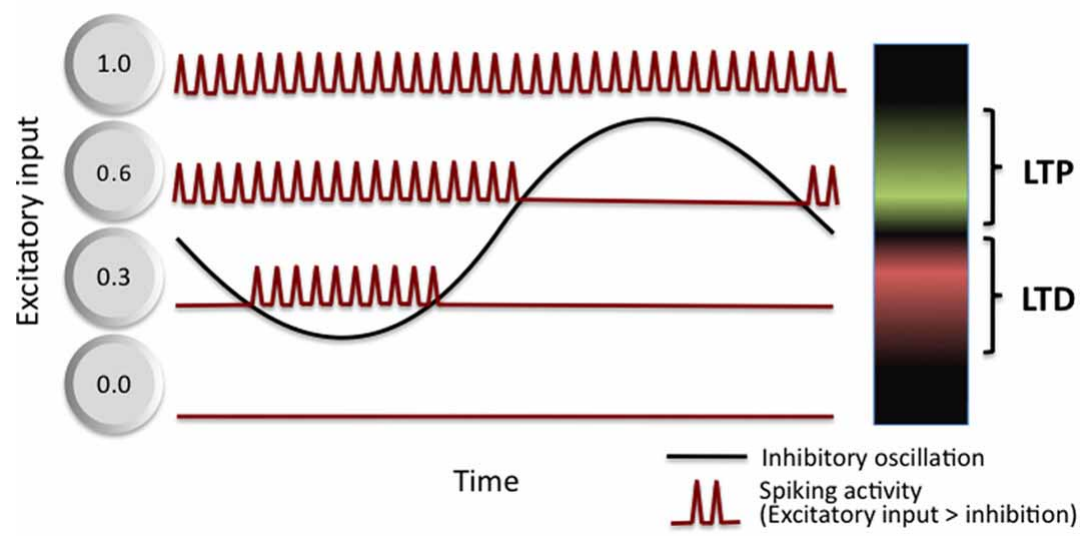

FIGURE 3 | Activation dynamics and plasticity in Norman et al. (2006) model of theta function. Inhibitory oscillations convert differences in the amount of excitation received by cells within a network into a time (phase) code. Three example cells are shown, each receiving a different amount of excitatory input: 0.0 - this cell receives no input and never activates, it incurs no LTP or LTD; 0.3-this cell receives moderate input and activates only during the trough of the oscillations, it incurs LTD as a result; and 0.6-this cell receives strong input and activates during more than half of the oscillation, it incurs LTP as a result. See text for additional details. 
serves to boost the signal to noise of memories by strengthening neurons that activate during the high inhibition phase (strongly active) and to weaken neurons that activate during the low inhibition phase (moderately active). Through a series of simulations, they demonstrate that such oscillation driven learning accelerates learning, improves pattern separation of correlated input patterns, boosts the memory capacity of neural networks (Norman et al., 2006), and accounts for counterintuitive behavioral performance on episodic memory tests in humans (Norman et al., 2007).

A prediction of this framework is that LTP versus LTD should be induced as a result of strong versus moderate excitation, respectively. Newman and Norman (2010) were able to verify this prediction by relating the trial-by-trial activation of cortical representations (as assessed with multivariate pattern analysis of scalp EEG data) to trial-by-trial behavioral performance. In the context of cholinergic modulation, this hypothesized relationship would additionally predict that local infusions of scopolamine into the hippocampus would alter the phases of theta at which tetanus stimulation would induce LTP. Specifically, because scopolamine would depress the afferent projections into CA1, each tetanic pulse would provide less excitation thereby shifting the baseline relationship between theta phase and excitation. Thus, there should exist a range of phases at which tetanus stimulation should induce LTD following a scopolamine infusion that would have induced LTP following a saline infusion.

\section{SPATIAL MEMORY}

While behavioral studies have provided clear evidence that acetylcholine plays an important role in spatial memory, a number of studies have also challenged this result. A recent comprehensive review of the role of acetylcholine and spatial memory by Deiana et al. (2011) includes discussion of both types of work; thus, we have restricted the scope of our review of these points to a few representative examples. We instead focus our attention on reviewing relevant findings from studies employing single unit recording techniques in awake behaving animals during manipulations of the cholinergic system. No formal computational models of the physiological influences of acetylcholine on spatial processing exist to our knowledge. Thus, instead, we present the oscillatory interference model of grid cell spatial tuning and suggest that acetylcholine may influence the spatial memory system utilizing theta rhythms as an intermediary.

\section{Mixed evidence regarding role of acetylcholine in spatial memory}

A wealth of evidence exists demonstrating a functional link between cholinergic function and spatial memory (see Deiana et al., 2011, for a comprehensive review). For example, in humans, administration of muscarinic antagonists prior to performing a virtual analog of the Morris water maze disrupts hippocampal activation as monitored through fMRI (Antonova et al., 2011). In rats, systemic administration of muscarinic antagonists to rats prior to the encoding phase of spatial memory has consistently been found to induce memory deficits in tasks such as the Morris water maze (e.g., Sutherland et al., 1982). Similarly, immunotoxic lesions of the cholinergic septo-hippocampal projection impair performance on the Morris water maze, in delayed non-match to position tasks on a T-maze, and on a win-shift radial arm maze task (e.g., Leanza et al., 1995; Janis et al., 1998; Johnson et al., 2002). Mice without the beta2 nicotinic receptor subunit exhibit reduced slow exploratory behavior and selective re-expression of the beta2 subunit in the VTA is sufficient to reestablish exploratory behavior (Maskos et al., 2005).

A number of studies have also failed to find deficits in spatial memory tasks following disruption of the cholinergic system (see Deiana et al., 2011 for extensive discussion of this point). In one such line of evidence, Baxter and colleagues have shown that manipulations, such as the selective deafferentation of the cholinergic projections from the basal forebrain for example, elicit minimal, if any, performance impairments on spatial memory tasks (e.g., Baxter and Gallagher, 1996; McMahan et al., 1997; Vuckovich et al., 2004). A separate line of work by Schallert and colleagues has also provided evidence of preserved spatial memory function despite severe disruption of the cholinergic system (Day and Schallert, 1996). Studies utilizing alpha7 nicotinic receptor knockout mice have found little impairment on spatial memory tasks (e.g., Paylor et al., 1998), but this may be the result of compensatory effects in light of a finding showing that reduced surface expression of alpha7 receptors subsequently does impair performance on the Morris water maze (Curzon et al., 2006).

\section{Unit recordings provide window into spatial processing}

The hippocampus and medial EC play crucial roles in navigation; lesions of either region lead to deficits on spatial memory tasks (e.g., Morris et al., 1982; Steffenach et al., 2005). The precise roles of such medial temporal lobe structures is a topic of debate and beyond the scope of this review (e.g., see Gray and McNaughton, 1983; McNaughton et al., 1996; Moser et al., 2008; Dickerson and Eichenbaum, 2010), for relevant viewpoints). However, unit recordings in the hippocampus and the medial EC have reliably found that the position of an animal is among the most clearly observable correlates of fluctuations in neuronal activity (e.g., O'Keefe and Dostrovsky, 1971; Ekstrom et al., 2003). Cells in the pyramidal cell layers of hippocampal regions CA1 and CA3, for example, preferentially fire in distinct subregions of testing enclosures, and, as such, have been termed place cells. Within the medial EC, Fyhn and colleagues (2004) found that cells fired action potentials, not at a single location like place cells, but rather, at multiple places, marking the vertices of a grid of equilateral triangles, earning them the label grid cells (Hafting et al., 2005).

The activity of spatially tuned cells of the hippocampus and EC is believed to provide a window into spatial information processing (e.g., Colgin et al., 2008 and the ensemble activity of spatially tuned populations of hippocampal and entorhinal cells is believed to serve as the substrate of spatial memory (e.g., McNaughton et al., 2006). As such, manipulations that alter the tuning of place cells or grid cells may, equally, provide insight into the mechanisms that subserve spatial memory.

\section{Cholinergic effects on unit recordings}

Evidence of the involvement of acetylcholine in deriving the spatial tuning of place cells and grid cell suggests multiple modes of interaction between spatially tuned cells and the cholinergic 
system. At a broad level, acetylcholine appears to play a role in the adaptive remapping of spatial tuning following environmental modifications. The location within a testing enclosure where a given cell fires maximally can differ from one enclosure to the next; subtle alterations of the testing enclosure are sufficient for inducing such remapping (Muller and Kubie, 1987), but do not guarantee that remapping occurs. Immuno-toxic lesions of the cholinergic projections into the hippocampus and EC significantly decrease the likelihood that remapping occurs upon entrance to a novel testing environment (Ikonen et al., 2002). Individual differences in the prepotency to remap following such alterations predict the level of spatial memory performance on an independent task (such as the Morris water maze task; e.g., Wilson et al., 2003).

At a more local level, evidence for involvement of acetylcholine in the local network effects responsible for resolving the tuning of place cells in the hippocampus comes from a study by Brazhnik et al. (2004), in which they recorded place cell activity during local infusions of scopolamine into the hippocampus. They found that such infusions lead to significant reductions in the reliability of place cell tuning as assessed both through shifts in place field position and through a decrease in the ratio of in-field versus outof-field spiking (see also, Brazhnik et al., 2003 for similar results). Unfortunately, the technical challenges inherent to stably recording from single units during local infusions have limited the study of the local influences of pharmacological agents. Evidence from a study employing systemic infusions of scopolamine, however, similarly suggests that entorhinal grid cells also depend critically on the cholinergic system to maintain their spatial tuning (Newman and Hasselmo, 2011). Specifically, they found that systemic infusions of scopolamine induce significant decreases in both the spatial and temporal periodicity of entorhinal grid cells. As such, spatial information processing in the hippocampus is subject to both local influences of acetylcholine (as shown by Brazhnik et al., 2004) and to the influences of cholinergic modulation on the entorhinal grid cells which are believed to serve as a source of spatial information that is ultimately reflected in the spatial correlates of CA1 and CA3 place cell activity (Moser et al., 2008).

\section{Theta may mediate role of acetylcholine in spatial processing}

The precise mechanism by which acetylcholine contributes to the tuning of place cells and grid cells is not clearly understood. A promising hypothesis is that the spatial tuning of such cells is affected by cholinergic modulation through an intermediary: theta rhythms (e.g., O'Keefe and Recce, 1993; Blair et al., 2007; Burgess et al., 2007; Hasselmo et al., 2007). Unit recordings of both place cells and grid cells provide compelling support for an intimate relationship between theta and the function of these cells. The spiking of both place cells and grid cells exhibits theta rhythmicity and theta phase locking, demonstrating a clear interaction between the two (e.g., O'Keefe and Recce, 1993; Hafting et al., 2005). Additionally, the existence of phase precession (i.e., the precession of spiking from late phases of theta to progressively earlier phases as a rat runs through a firing field) in both place cells and layer II and V grid cells further suggests an intimate relationship between theta and the representation of space in the hippocampus and medial EC (O’Keefe and Recce, 1993; Hafting et al., 2008).

It is possible that the correspondence between the activity of spatially tuned cells and theta does not reflect a functional link, but rather, results from a shared involvement in medial temporal lobe processing. To test this, Brandon and colleagues (2011) tracked the spatial and temporal periodicity of entorhinal grid cells as they temporarily blocked theta oscillations in the hippocampus and EC via infusions of muscimol (a GABA(A) agonist) into the medial septum. They found that both the spatial tuning and theta rhythmicity of the grid cells was significantly reduced following the inactivation of the medial septum. Further, they found that the time course of the recovery of the spatial tuning paralleled the time course of the recovery of theta amplitude. A similar pattern of results was also found by Koenig et al. (2011). These findings strongly support the hypothesis that the spatial tuning of grid cells is functionally linked to theta rhythms.

Inactivation of the medial septum also influences hippocampal place cells (in both CA1 and CA3), but in a less robust fashion. Koenig et al. (2011), for example, found a significant but modest (relative to the grid cells) reduction in the correlation of the spatial tuning of place cells following the inactivation of the medial septum. Similarly, Shapiro et al. (1989) found that the spatial tuning of place cells on a radial arm maze becomes more dispersed and more easily disrupted following lesions of the fornix (see also Miller and Best, 1980). Interestingly, Shapiro et al. (1989) also found that the fornix-lesion induced changes were partially reversed following intrahippocampal grafts of fetal basal forebrain tissue rich in cholinergic neurons, reinforcing the hypothesis that diffuse release of acetylcholine facilitates the tuning of place cells.

\section{Oscillatory interference model}

Mechanistically, Burgess et al. (2007) suggested that theta may drive the formation of the spatial tuning pattern observed in entorhinal grid cells as a result of multiple oscillators coming into and out-of phase with each other as a rat moves. At its essence, the model suggests that grid cells fire when the sum of at least two oscillators crosses a threshold. Importantly, the frequency of each oscillator is determined by the speed of the animal in a particular heading (e.g., north) — that is, when the rat is moving in the preferred direction (north in this example) the frequency of that oscillator increases proportional to the speed of the animal. If however, the animal moves in a direction orthogonal to the preferred direction (e.g., west), the oscillator returns back to a baseline frequency, assumed to be in the theta band, to indicate a zero magnitude projection on the preferred direction. The preferred direction of the two oscillators is assumed to differ by an integer multiple of $60^{\circ}$. When two such velocity controlled oscillators are summed and thresholded, the interference pattern closely resembles the spatial tuning pattern of entorhinal grid cells. This is summarized in Figure 4. Several variants of this oscillatory interference model of grid cell formation have since been described to address challenges faced by the first version of this model (e.g., Blair et al., 2008; Burgess, 2008; Hasselmo, 2008, 2009; Hasselmo et al., 2009; Zilli and Hasselmo, 2010). 


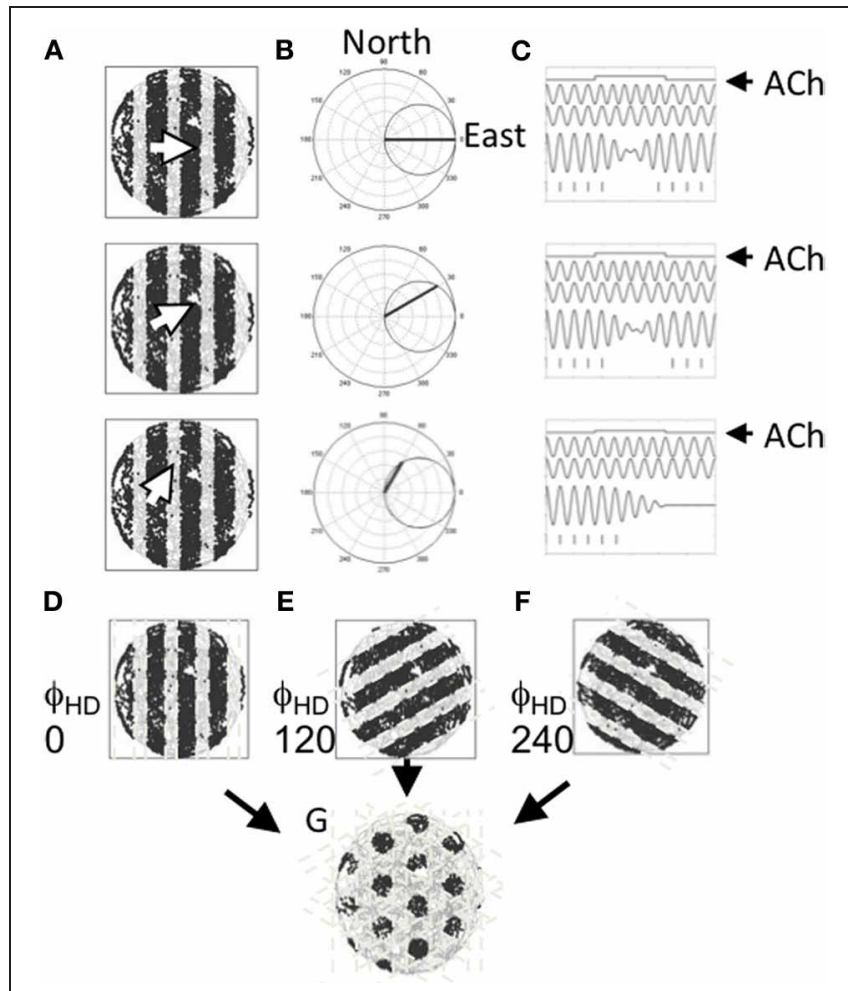

FIGURE 4 | Suggested role for acetylcholine in driving the tuning of grid cells. (A) Three example movements are shown by the white arrow in a circular arena. The cardinal direction of each of these movements is projected onto a set of cells cosine tuned to fire in a specific direction. (B) The movement direction for the examples shown in (A) are shown projected onto an example directionally tuned cell that prefers head directions pointing east. (C) Differences in the strength of the projection onto the head direction cell changes the rate at which two oscillators phase shift inducing an oscillatory interference pattern. Movement is depicted as a step function (top line). The movement causes one of two oscillators (the second line) to shift frequency changing its phase alignment to a baseline oscillator (the third line) so that summation of the oscillators shifts from constructive interference to destructive interference and back again (the fourth line). Windows of constructive interference induce activity in a cell in which these oscillations are summed (hash marks shown at the bottom). (D-F) Patterns of constructive and destructive interference shown for cells with three different preferred headings. (G) The pattern of constructive interference resembling the firing pattern of an entorhinal grid cell that results from the summation of three oscillators that reflect movement in three headings spaced by $120^{\circ}$

Oscillatory interference models have provided a number of testable predictions that have since been supported by empirical evidence. Most clearly, the model predicts that grid cell tuning requires an intact theta rhythm. The findings of Brandon et al. (2011) provide clear support for this prediction in that medial septal inactivation both significantly reduced the amplitude of theta oscillations and significantly decreased the spatial tuning of grid cells. Additionally, the model predicted that shifts in firing field spacing observed along the dorsal-ventral axis of the hippocampus should correspond to differences in the frequency of intrinsic oscillators along the same axis (Burgess et al., 2007). Consistent with this hypothesis, Giocomo and Hasselmo
(2007) found that the frequency of subthreshold membrane oscillations in stellate cells (putative grid cells) was significantly faster in dorsal medial EC (3.8 and $4.9 \mathrm{~mm}$ below the dorsal surface of the brain) than ventral medial EC (between 4.9 and $7.1 \mathrm{~mm}$ below the dorsal surface of the brain, see also Giocomo and Hasselmo, 2008, 2009; Yoshida et al., 2011). Finally, Jeewajee et al. (2008) found that the rhythmic firing of grid cells increased with running speed as was further predicted by the model.

The central role of theta oscillations in the oscillatory interference models, by proxy, instills an important role for acetylcholine in the regulation and maintenance of the spatial tuning of grid cells. For example, given the purported role of acetylcholine in modulating theta frequency (e.g., Givens and Olton, 1995), it is likely that environmental factors that alter acetylcholine release would impact the grid cell network. For example, novelty triggers increased acetylcholine release (e.g., Acquas et al., 1996; Giovannini et al., 2001) and decreased theta frequency (e.g., Jeewajee et al., 2008). As such, the oscillatory interference model suggests that novelty should result in the expansion of grid field spacing. This result was supported by a unit recording study performed by Barry et al. $(2009,2012)$, in which, they found that the spacing of grid cells expanded by as much as $40 \%$ when rats were first placed in a novel testing enclosure. As the rats gained experience with the enclosure, the size of the fields gradually decreased their spacing. Also consistent with this prediction, Heys et al. (2010) demonstrated that, in vitro, bath application of carbachol reduced the resonant frequency of layer II stellate cells.

\section{SYNTHESIS AND SUMMARY}

Our goal, in this review, was to highlight the important role that computational models have played in linking the empirical work that has been done on the physiological and cognitive influences of acetylcholine. The symbiotic relationship between computational theory, physiology, and behavior is particularly strong in the case of acetylcholine due to the multitude of influences that acetylcholine has, particularly at the physiological level. These influences frequently appear contradictory (e.g., ability to cause both enhanced LTP and acute presynaptic inhibition of synaptic potentials) but can be shown to have a coherent cognitive function through simulation (e.g., allow for stimuli to be clearly represented without previously formed memories obscuring the perception). In each case, the models first provide a coherent framework to account for existing data but then serve their true function second: to provide testable hypotheses that serve to focus new empirical explorations. A wide variety of models were described in this review, each offering a distinct view on acetylcholine and each with different implications for future research. Thus, by way of synthesis, the remainder of this manuscript will aim to catalog these views and implications as well as to highlight important unanswered questions in the empirical and theoretical domains. Because the connection between cholinergic function and spatial memory, in particular, remains poorly understood, we focus on drawing points of potential contact between each of the previously described mechanisms and spatial processing. 


\section{Persistent spiking}

Acetylcholine activates a calcium-sensitive non-specific cation current $\left(\mathrm{I}_{\mathrm{CAN}}\right)$ in some medial EC neurons that allows for these cells to spike persistently following a single pulse of stimulation in slice preparations (e.g., Klink and Alonso, 1997). Although already discussed in the context of working memory, it is possible that this mechanism additionally contributes to spatial information processing. For example, persistent spiking cells have been proposed to play the role of the velocity controlled oscillators in a variant of the oscillatory interference model of grid cell tuning (Hasselmo, 2008). As such, the degraded spatial tuning of grid cells observed following systemic infusions of scopolamine may result from the disruption of the firing of persistent spiking cells in the absence of cholinergic activation of $\mathrm{I}_{\mathrm{CAN}}$. Additional investigation, specifically on the influences of local infusions of scopolamine, into the medial EC, on grid cells is required before strong conclusions can be drawn on this hypothesis.

\section{Gating of extrinsic afferent projections}

Acetylcholine simultaneously boosts the strength of afferent projections while depressing the strength of intrinsic projections (e.g., Hasselmo and Bower, 1992). Modeling has shown that these effects serve to enhance the encoding of new representations to support processing of environmental stimuli (e.g., Hasselmo et al., 1992) or to allow contextual cues to disambiguate perceptual processing (Yu and Dayan, 2005). Both processes are likely to play important roles for spatial information processing. Empirically, this can be explored through analyses of inter regional coherence of local field potential signals. Several exciting recent studies employing these techniques have revealed insights into the means by which anatomically distinct areas communicate (Buschman and Miller, 2007; Colgin et al., 2009), however, none have yet to investigate the influence of cholinergic modulation on such interregional coherence metrics.

\section{Gating of synaptic plasticity}

In parallel to its modulation of projection strengths, acetylcholine reduces the threshold for the induction of LTP (e.g., Huerta and Lisman, 1995). An implication of these results is that, under circumstances of depleted acetylcholine, processing of environmental stimuli is likely to occur more slowly and less effectively. Further, even once stimuli are successfully represented little benefit of this processing can be reaped on subsequent encounters with the relevant environmental stimuli as a result of the high threshold for the induction of LTP. As such, cholinergic blockade is likely to elicit particularly strong deficits in the processing of new stimuli (Sarter et al., 2005). In the context of spatial memory tasks, this suggests that novel testing enclosures and task demands, for which the subject has no adequate neural representation, will be most likely to elicit strong behavioral deficits following depletion of acetylcholine.

\section{Top-down recruitment of control}

One of the few sources of regulatory input into the basal forebrain from neocortex originates in the frontal cortex (Carnes et al., 1990). This input is attributed with the function of exerting top-down control over the cholinergic system. For example, this projection is likely to allow for top-down recruitment of attentional effort (e.g., Sarter et al., 2006). In the domain of spatial memory, this suggests that deficits are likely to be observed when the subject must exert top-down control over a maladaptive behavioral strategy. For example, systemic administration of muscarinic antagonists induces abnormal behaviors such as increased stereotypy and locomotor activity. This has been described by Schallert et al. (1980) who reported that rats can become "trapped" by simple environmental features such as corners or dead-ends of a track. They describe, for example, how rats can become stuck in a loop of stereotyped vertical or horizontal scanning movements at the dead-end of a linear track, in which they fail to ever turn around to face the open end of the track. Modification of the track to eliminate dead-ends (e.g., through the use of a circle track) can prevent trapping from occurring. Alternately, DeVietti et al. (1985) found that pre-exposure of the testing apparatus prior to infusion of atropine significantly reduced the time required to become un-trapped, for example by the dead-end.

Relatedly, Day and Schallert (1996) argued that impairments of spatial memory, as assessed in the Morris water maze, following cholinergic blockade were the result of a deficit in effective strategy selection, not in spatial processing. To test this hypothesis, they assessed the rate of learning in a Morris water maze task for animals administered a systemic injection of atropine relative to animals administered saline infusions. Critically, they employed a training protocol designed to promote the use of a spatial search strategy. Specifically, they utilized a training protocol in which the escape platform used on the first trials was almost as large as the tank. Then, over trials, the platform was replaced with smaller and smaller platforms until it had effectively shrunk into a specific quadrant of the tank. They found no difference in the rate of learning or difference in behavior on the final probe trial. They suggest that this finding indicates that cholinergic block does not impair spatial processing, but rather, the selection of a proper search strategy.

\section{New models of cholinergic function}

Amperometric monitoring of acetylcholine demonstrates that cholinergic modulation occurs at both fast and slow timescales (e.g., Parikh et al., 2007). This raises questions about the functional consequences of these different regimes. These time course effects are particularly difficult to intuit given the diversity of cholinergic receptor subtypes, each with different desensitization rates and distinct physiological influences. Thus, a fruitful avenue for future models would be to characterize the functional properties of each of these regimes.

\section{CONCLUSIONS}

We have described a number of models linking the behavioral role of acetylcholine to specific cellular effects of acetylcholine. Specifically, models of the modulation of cellular persistent spiking by acetylcholine suggest a mechanism for active maintenance in working memory that might also contribute to the path integration mechanisms underlying grid cell responses. Models of cholinergic modulation of circuit dynamics, such as 
the strength of afferent input relative to recurrent feedback and threshold for the induction of LTP versus LTD, provide a framework for understanding the role of acetylcholine in enhancing attention to sensory stimuli and encoding of memories. Finally, models of network theta rhythm oscillations suggest how theta may serve as an intermediary between cholinergic regulation and episodic and spatial memory function. Unit recording studies in cortical structures serve to connect what has been learned about the physiological influences of acetylcholine in vitro to behavioral

\section{REFERENCES}

Acquas, E., Wilson, C., and Fibiger, H. C. (1996). Conditioned and unconditioned stimuli increase frontal cortical and hippocampal acetylcholine release: effects of novelty, habituation, and fear. J. Neurosci. 16, 3089-3096.

Adams, S. V., Winterer, J., and Müller, W. (2004). Muscarinic signaling is required for spike-pairing induction of long-term potentiation at rat schaffer collateral-CA1 synapses. Hippocampus 14, 413-416.

Albuquerque, E. X., Pereira, E. F. R., Alkondon, M., and Rogers, S. W. (2009). Mammalian nicotinic acetylcholine receptors: from structure to function. Physiol. Rev. 89, $73-120$.

Alkondon, M., Pereira, E., Eisenberg, H., and Albuquerque, E. (1999). Choline and selective antagonists identify two subtypes of nicotinic acetylcholine receptors that modulate GABA release from CA1 interneurons in rat hippocampal. J. Neurosci. 19, 2693-2705.

Alkondon, M., Pereira, E. F., Barbosa, C. T., and Albuquerque, E. X. (1997). Neuronal nicotinic acetylcholine receptor activation modulates gamma-aminobutyric acid release from CA1 neurons of rat hippocampal slices. J. Pharmacol. Exp. Ther. 283, 1396-1411.

Antonova, E., Parslow, D., Brammer, M., Simmons, A., Williams, S., Dawson, G. R., and Morris, R. (2011). Scopolamine disrupts hippocampal activity during allocentric spatial memory in humans: an fMRI study using a virtual reality analogue of the Morris Water Maze. J. Psychopharmacol. 25, 1256-1265.

Arnold, H. M., Burk, J. A., Hodgson, E. M., Sarter, M., and Bruno, J. P. (2002). Differential cortical acetylcholine release in rats performing a sustained attention task versus behavioral control tasks that do not explicitly tax attention. Neuroscience 114, 451-460.

Asaad, W. F., Rainer, G., and Miller, E. K. (1998). Neural activity in the primate prefrontal cortex during associative learning. Neuron 21, 1399-1407.

Asaka, Y., Griffin, A. L., and Berry, S. D. (2002). Reversible septal inactivation disrupts hippocampal slow-wave and unit activity and impairs trace conditioning in rabbits (Oryctolagus cuniculus). Behav. Neurosci. 116, 434-442.

Asaka, Y., Seager, M. A., Griffin, A. L., and Berry, S. D. (2000). Medial septal microinfusion of scopolamine disrupts hippocampal activity and trace jaw movement conditioning. Behav. Neurosci. 114, 1068-1077.

Bachevalier, J., and Mishkin, M. (1986). Visual recognition impairment follows ventromedial but not dorsolateral prefrontal lesions in monkeys. Behav. Brain Res. 20, 249-261.

Baddeley, A. (2000). The episodic buffer: a new component of working memory? Trends Cogn. Sci. 4, 417-423.

Baddeley, A., and Wilson, B. A. (2002). Prose recall and amnesia: implications for the structure of working memory. Neuropsychologia 40, 1737-1743.

Bang, S. J., and Brown, T. H. (2009). Muscarinic receptors in perirhinal cortex control trace conditioning. J. Neurosci. 29, 4346-4350.

Barbagallo, B., Prescott, H. A., Boyle, P., Climer, J., and Francis, M. M. (2010). A dominant mutation in a neuronal acetylcholine receptor subunit leads to motor neuron degeneration in Caenorhabditis elegans. J. Neurosci. 30, 13932-13942.

Barry, C., Heys, J. G., and Hasselmo, M. E. (2012). Possible role of acetylcholine in regulating spatial novelty effects on theta rhythm and grid cells. Front. Neural Circuits 6:5. doi: 10.3389/fncir.2012.00005

Barry, C., O'Keefe, J., and Burgess, N. (2009). Effect of novelty on grid cell firing. Soc. Neurosci. Abstr. 35, 101.24 .

Baxter, M. G., and Gallagher, M. (1996). Intact spatial learning in both young and aged rats following selective removal of hippocampal

effects. Such studies have provided support for existing models but additional unit recording studies will be necessary to further develop models linking behavioral function to the specific cellular effects of acetylcholine in cortical structures.

\section{ACKNOWLEDGMENTS}

This work was supported by National Institute of Mental Health F32 MH090671, R01 MH60013, R01 MH61492, and the Office of Naval Research MURI award N00014-10-1-0936.

cholinergic input. Behav. Neurosci. 110, 460-467.

Bear, M. F., and Singer, W. (1986). Modulation of visual cortical plasticity by acetylcholine and noradrenaline. Nature 320, 172-176.

Beatty, W. W., Butters, N., and Janowsky, D. S. (1986). Patterns of memory failure after scopolamine treatment: implications for cholinergic hypotheses of dementia. Behav. Neural Biol. 45, 196-211.

Blair, H. T., Gupta, K., and Zhang, K. (2008). Conversion of a phase- to a rate-coded position signal by a three-stage model of theta cells, grid cells, and place cells. Hippocampus $18,1239-1255$

Blair, H. T., Welday, A. C., and Zhang, K. (2007). Scale-invariant memory representations emerge from moire interference between grid fields that produce theta oscillations: a computational model. J. Neurosci. 27, 3211-3229.

Blitzer, R. D., Gil, O., and Landau, E. M. (1990). Cholinergic stimulation enhances long-term potentiation in the CAl region of rat hippocampus. Neurosci. Lett. 119, 207-210.

Bohme, G. A., Letchworth, S. R., PiotGrosjean, O., Gatto, G. J., Obinu, M. C., Caldwell, W. S., Laville, M., Brunel, P., Pellerin, R., Leconte, J. P., Genevois-Borella, A., Dubedat, P., Mazadier, M., Pradier, L., Bencherif, M., and Benavides, J. (2004). In vitro and in vivo characterization of TC1827 , a novel brain $\alpha 4 \beta 2$ nicotinic receptor agonist with pro-cognitive activity. Drug Dev. Res. 62, 26-40.

Brandon, M. P., Bogaard, A. R., Libby, C. P., Connerney, M. A., Gupta, K., and Hasselmo, M. E. (2011). Reduction of theta rhythm dissociates grid cell spatial periodicity from directional tuning. Science 332, 595-599.

Brazhnik, E., Borgnis, R., Muller, R. U. and Fox, S. E. (2004). The effects on place cells of local scopolamine dialysis are mimicked by a mixture of two specific muscarinic antagonists. J. Neurosci. 24, 9313-9323.

Brazhnik, E. S., Muller, R. U., and Fox, S. E. (2003). Muscarinic blockade slows and degrades the locationspecific firing of hippocampal pyramidal cells. J. Neurosci. 23, 611-621.

Broks, P., Preston, G. C., Traub, M., Poppleton, P., Ward, C., and Stahl, S. M. (1988). Modelling dementia: effects of scopolamine on memory and attention. Neuropsychologia 26, 685-700.

Burgess, N. (2008). Grid cells and theta as oscillatory interference: theory and predictions. Hippocampus 18 , 1157-1174.

Burgess, N., Barry, C., and O'Keefe, J. (2007). An oscillatory interference model of grid cell firing. Hippocampus 812, 801-812.

Buschman, T. J., and Miller, E. K. (2007). Top-down versus bottomup control of attention in the prefrontal and posterior parietal cortices. Science 315, 1860-1862.

Buzsaki, G. (2002). Theta oscillations in the hippocampus. Neuron 33, 325-340.

Buzsaki, G., Leung, L. W., and Vanderwolf, C. H. (1983). Cellular bases of hippocampal EEG in the behaving rat. Brain Res. 287, 139-171.

Carnes, K. M., Fuller, T. A., and Price, J. L. (1990). Sources of presumptive glutamater- gic/aspartatergic afferents to the magnocellular basal forebrain in the rat. J. Comp. Neurol. 302, 824-852.

Chan, W. K., Wong, P. T. H., and Sheu, F. S. (2007). Frontal cortical alpha7 and alpha4beta2 nicotinic acetylcholine receptors in working and reference memory. Neuropharmacology 52, 1641-1649.

Cheong, M. Y., Yun, S. H., MookJung, I., Joo, I., Huh, K., and Jung, M. W. (2001). Cholinergic modulation of synaptic physiology in deep layer entorhinal cortex of the rat. J. Neurosci. Res. 66, 117-121.

Cole, A. E., and Nicoll, R. A. (1984). The pharmacology of cholinergic excitatory responses in hippocampal pyramidal cells. Brain Res. 305, 283-290.

Colgin, L. L., Denninger, T., Fyhn, M., Hafting, T., Bonnevie, T., Jensen, O., Moser, M. B., and Moser, E. I. 
(2009). Frequency of gamma oscillations routes flow of information in the hippocampus. Nature 462, 353-357.

Colgin, L. L., Moser, E. I., and Moser, M. B. (2008). Understanding memory through hippocampal remapping. Trends Neurosci. 31, 469-477.

Corkin, S. (1984). Lasting consequences of bilateral medial temporal lobectomy: clinical course and experimental findings in H.M. Semin. Neurol. 4, 249-259.

Crow, T. J., and Grove-White, L. G. (1973). An analysis of the learning deficit following hyoscine administration to man. Br. J. Pharmacol. 49, 322-327.

Croxson, P. L., Kyriazis, D. A., and Baxter, M. G. (2011). Cholinergic modulation of a specific memory function of prefrontal cortex. Nat. Neurosci. 14, 1510-1512.

Curzon, P. P., Anderson, D. J. D., Nikkel, A. L. A., Fox, G. B. G., Gopalakrishnan, M. M., Decker, M. W. M., and Bitner, R. S. R. (2006). Antisense knockdown of the rat alpha7 nicotinic acetylcholine receptor produces spatial memory impairment. Neurosci. Lett. 410, 15-19.

Dalley, J. W., McGaughy, J., O'Connell, M. T., Cardinal, R. N., Levita, L., and Robbins, T. W. (2001). Distinct changes in cortical acetylcholine and noradrenaline efflux during contingent and noncontingent performance of a visual attentional task. J. Neurosci. 21, 4908-4914.

Dalley, J. W., Theobald, D. E., Bouger, P., Chudasama, Y., Cardinal, R. N., and Robbins, T. W. (2004). Cortical cholinergic function and deficits in visual attentional performance in rats following 192 IgG-saporininduced lesions of the medial prefrontal cortex. Cereb. Cortex 14, 922-932.

Dasari, S., and Gulledge, A. T. (2011). M1 and M4 receptors modulate hippocampal pyramidal neurons. J. Neurophysiol. 105, 779-792.

Day, L. B., and Schallert, T. (1996). Anticholinergic effects on acquisition of place learning in the Morris water task: spatial mapping deficit or inability to inhibit nonplace strategies? Behav. Neurosci. 110, 998-1005.

Deco, G., and Thiele, A. (2009). Attention - oscillations and neuropharmacology. Eur. J. Neurosci. 30, 347-354

Degroot, A., Wolff, M. C., and Nomikos, G. G. (2005). Acute exposure to a novel object during consolidation enhances cognition. Neuroreport 16, 63-67.
Deiana, S., Platt, B., and Riedel, G. (2011). The cholinergic system and spatial learning. Behav. Brain Res. 221, 389-411.

Descarries, L., Gisiger, V., and Steriade, M. (1997). Diffuse transmission by acetylcholine in the CNS. Prog. Neurobiol. 53, 603-625.

DeVietti, T. L., Pellis, S. M., Pellis, V. C., and Teitelbaum, P. (1985). Previous experience disrupts atropine-induced stereotyped "trapping" in rats. Behav. Neurosci. 99, 1128-1141.

Dickerson, B. C., and Eichenbaum, H. (2010). The episodic memory system: neurocircuitry and disorders. Neuropsychopharmacology 35, 86-104

Disney, A. A., and Aoki, C. (2008) Muscarinic acetylcholine receptors in macaque $\mathrm{V} 1$ are most frequently expressed by parvalbuminimmunoreactive neurons. J. Comp. Neurol. 507, 1748-1762.

Disney, A. A., Aoki, C., and Hawken, M. J. (2007). Gain modulation by nicotine in macaque v1. Neuron 56 , 701-713.

Disney, A. A., Domakonda, K. V., and Aoki, C. (2006). Differential expression of muscarinic acetylcholine receptors across excitatory and inhibitory cells in visual cortical areas $\mathrm{V} 1$ and $\mathrm{V} 2$ of the macaque monkey. J. Comp. Neurol. 499, 49-63.

Eacott, M. J., Gaffan, D., and Murray, E. A. (1994). Preserved recognition memory for small sets, and impaired stimulus identification for large sets, following rhinal cortex ablations in monkeys. Eur. J. Neurosci. 6, 1466-1478.

Easton, A., Fitchett, A. E., Eacott, M. J., and Baxter, M. G. (2010). Medial septal cholinergic neurons are necessary for context-place memory but not episodic-like memory. Hippocampus 21, 1021-1027.

Egorov, A. V., Hamam, B. N., Fransen, E., Hasselmo, M. E., and Alonso, A A. (2002). Graded persistent activity in entorhinal cortex neurons. Nature 420, 173-178.

Ekstrom, A. D., Kahana, M. J., Caplan, J. B., Fields, T. A., Isham, E. A., Newman, E. L., and Fried, I. (2003). Cellular networks underlying human spatial navigation. Nature 425, 184-188.

Ernst, M., Heishman, S. J., Spurgeon, L., and London, E. D. (2001). Smoking history and nicotine effects on cognitive performance. Neuropsychopharmacology 25, 313-319.

Esclassan, F., Coutureau, E., Di Scala, G., and Marchand, A. R. (2009).
A cholinergic-dependent role for the entorhinal cortex in trace fear conditioning. J. Neurosci. 29, 8087-8093.

Everitt, B. J., and Robbins, T. W (1997). Central cholinergic systems and cognition. Annu. Rev. Psychol. $48,649-684$.

Fadel, J. R. (2011). Regulation of cortical acetylcholine release: insights from in vivo microdialysis studies. Behav. Brain Res. 221 527-536.

Faiman, C. P., de Erausquin, G. A. and Baratti, C. M. (1991). The enhancement of retention induced by vasopressin in mice may be mediated by an activation of central nicotinic cholinergic mechanisms. Behav. Neural Biol. 56, 183-199.

Fransén, E., Alonso, A. A., and Hasselmo, M. E. (2002). Simulations of the role of the muscarinic-activated calciumsensitive nonspecific cation current INCM in entorhinal neuronal activity during delayed matching tasks. J. Neurosci. 22, 1081-1097.

Friedman, J. I. (2004). Cholinergic targets for cognitive enhancement in schizophrenia: focus on cholinesterase inhibitors and muscarinic agonists. Psychopharmacology 174, 45-53.

Fujii, S., Ji, Z., Morita, N., and Sumikawa, K. (1999). Acute and chronic nicotine exposure differentially facilitate the induction of LTP. Brain Res. 846, 137-143.

Fujisawa, S., Amarasingham, A. Harrison, M. T., and Buzsaki, G. (2008). Behavior-dependent short-term assembly dynamics in the medial prefrontal cortex. Nat. Neurosci. 11, 823-833.

Fuster, J. M. (1973). Unit activity in prefrontal cortex during delayedresponse performance: neuronal correlates of transient memory. J. Neurophysiol. 36, 61-78.

Fyhn, M., Molden, S., Witter, M. P., Moser, E. I., and Moser, M.-B. (2004). Spatial representation in the entorhinal cortex. Science 305 1258-1264.

Gaffan, D., and Murray, E. A. (1992). Monkeys (Macaca fascicularis) with rhinal cortex ablations succeed in object discrimination learning despite 24-hr intertrial intervals and fail at matching to sample despite double sample presentations. Behav. Neurosci. 106, 30-38.

Ghoneim, M. M., and Mewaldt, S. P. (1975). Effects of diazepam and scopolamine on storage, retrieval and organizational processes in memory. Psychopharmacology 44 257-262.
Gil, Z., Conners, B. W., and Amitai, Y. (1997). Differential regulation of neocortical synapses by neuromodulators and activity. Neuron 19 , 679-686.

Giocomo, L. M., and Hasselmo, M. E. (2005). Nicotinic modulation of glutamatergic synaptic transmission in region CA3 of the hippocampus. Eur. J. Neurosci. 22, 1349-1356.

Giocomo, L. M., and Hasselmo, M. E. (2007). Neuromodulation by glutamate and acetylcholine can change circuit dynamics by regulating the relative influence of afferent input and excitatory feedback. Mol. Neurobiol. 36, 184-200.

Giocomo, L. M., and Hasselmo, M. E. (2008). Time constants of h current in layer II stellate cells differ along the dorsal to ventral axis of medial entorhinal cortex. J. Neurosci. 28, 9414-9425.

Giocomo, L. M., and Hasselmo, M. E. (2009). Knock-out of HCN1 subunit flattens dorsal-ventral frequency gradient of medial entorhinal neurons in adult mice. J. Neurosci. 29, 7625-7630.

Giovannini, M. G., Rakovska, A. Benton, R. S., Pazzagli, M., Bianchi, L., and Pepeu, G. (2001). Effects of novelty and habituation on acetylcholine, GABA, and glutamate release from the frontal cortex and hippocampus of freely moving rats. Neuroscience 106, 43-53.

Givens, B., and Olton, D. S. (1995) Bidirectional modulation of scopolamine-induced working memory impairments by muscarinic activation of the medial septal area. Neurobiol. Learn. Mem. 63, 269-276.

Gold, P. E. (2003). Acetylcholine modulation of neural systems involved in learning and memory. Neurobiol. Learn. Mem. 80, 194-210.

Gray, J. A., and McNaughton, N. (1983). Comparison between the behavioural effects of septal and hippocampal lesions: a review. Neurosci. Biobehav. Rev. 7, 119-188.

Gray, R., Rajan, A. S., Radcliffe, K. A., Yakehiro, M., and Dani, J. A. (1996). Hippocampal synaptic transmission enhanced by low concentrations of nicotine. Nature 383, 713-716.

Green, A., Ellis, K. A., Ellis, J., Bartholomeusz, C. F., Ilic, S., Croft, R. J., Luan Phan, K., and Nathan, P. J. (2005). Muscarinic and nicotinic receptor modulation of object and spatial n-back working memory in humans. Pharmacol. Biochem. Behav. 81, 575-584.

Green, J. D., and Arduini, A. A. (1954). Hippocampal electrical activity 
in arousal. J. Neurophysiol. 17, 533-557.

Griffin, A. L., Asaka, Y., Darling, R. D., and Berry, S. D. (2004). Theta-contingent trial presentation accelerates learning rate and enhances hippocampal plasticity during trace eyeblink conditioning. Behav. Neurosci. 118, 403-411.

Grove, E. A. (1988). Neural associations of the substantia innominata in the rat: afferent connections. J. Comp. Neurol. 277, 315-346.

Gupta, K., Keller, L. A., and Hasselmo, M. E. (2012). Reduced spiking in entorhinal cortex during the delay period of a cued spatial response task. Learn. Mem. 19, 219-230.

Hafting, T., Fyhn, M., Bonnevie, T., Moser, M. B. B., and Moser, E. I. (2008). Hippocampus-independent phase precession in entorhinal grid cells. Nature 453, 1248-1252.

Hafting, T., Fyhn, M., Molden, S., Moser, M. B., and Moser, E. I. (2005). Microstructure of a spatial map in the entorhinal cortex. Nature 436, 801-806.

Hasselmo, M. (1999). Neuromodulation: acetylcholine and memory consolidation. Trends Cogn. Sci. 3, 351-359.

Hasselmo, M. E. (1994). Runaway synaptic modification in models of cortex: implications for Alzheimer's disease. Neural Netw. 7, 13-40.

Hasselmo, M. E. (1997). A computational model of the progression of Alzheimer's disease. M.D. comput. 14, 181-191.

Hasselmo, M. E. (2006). The role of acetylcholine in learning and memory. Curr. Opin. Neurobiol. 16, 710-715.

Hasselmo, M. E. (2008). Grid cell mechanisms and function: contributions of entorhinal persistent spiking and phase resetting. Hippocampus 18, 1213-1229.

Hasselmo, M. E. (2009). A model of episodic memory: mental time travel along encoded trajectories using grid cells. Neurobiol. Learn. Mem. 92, 559-573.

Hasselmo, M. E., Anderson, B. P., and Bower, J. M. (1992). Cholinergic modulation of cortical associative memory function. J. Neurophysiol. 67, 1230-1246.

Hasselmo, M. E., Brandon, M. P., Yoshida, M., Giocomo, L. M., Heys, J. G., Fransen, E., Newman, E. L., and Zilli, E. A. (2009). A phase code for memory could arise from circuit mechanisms in entorhinal cortex. Neural Netw. 22, 1129-1138.

Hasselmo, M. E., Bodelón, C., and Wyble, B. P. (2002). A proposed function for hippocampal theta rhythm: separate phases of encoding and retrieval enhance reversal of prior learning. Neural Comput. 14, 793-817.

Hasselmo, M. E., and Bower, J. M. (1992). Cholinergic suppression specific to intrinsic not afferent fiber synapses in rat piriform (olfactory) cortex. J. Neurophysiol. 67, 1222-1229.

Hasselmo, M. E., and Bower, J. M. (1993). Acetylcholine and memory. Trends Neurosci. 16, 218-222.

Hasselmo, M. E., Giocomo, L. M., and Zilli, E. A. (2007). Grid cell firing may arise from interference of theta frequency membrane potential oscillations in single neurons. Hippocampus 17, 1252-1271.

Hasselmo, M. E., and Sarter, M. (2011). Modes and models of forebrain cholinergic neuromodulation of cognition. Neuropsychopharmacology 36, 52-73.

Hasselmo, M. E., and Schnell, E. (1994). Laminar selectivity of the cholinergic suppression of synaptic transmission in rat hippocampal region CA1, computational modeling and brain slice physiology. J. Neurosci. 14, 3898-3914.

Hasselmo, M. E., and Stern, C. E. (2006). Mechanisms underlying working memory for novel information. Trends Cogn. Sci. 10, 487-493.

Hasselmo, M. E., Schnell, E., and Barkai, E. (1995). Dynamics of learning and recall at excitatory recurrent synapses and cholinergic modulation in rat hippocampal region CA3. J. Neurosci. 15, 5249-5262.

Hensch, T. K. (2004). Critical period regulation. Annu. Rev. Neurosci. 27, 549-579.

Herrero, J. L., Roberts, M. J., Delicato, L. S., Gieselmann, M. A., Dayan, P., and Thiele, A. (2008). Acetylcholine contributes through muscarinic receptors to attentional modulation in V1. Nature 454, 1110-1114.

Heys, J. G., Giocomo, L. M., and Hasselmo, M. E. (2010). Cholinergic modulation of the resonance properties of stellate cells in layer II of medial entorhinal cortex. J. Neurophysiol. 104, 258-270.

Heys, J. G., Schultheiss, N. W., Shay, C. F., and Hasselmo, M. E. (2012). Effects of acetylcholine on neuronal properties in entorhinal cortex: a review of acetylcholine and the entorhinal cortex. Front. Neurosci.

Himmelheber, A. M., Sarter, M., and Bruno, J. P. (1997). Operant performance and cortical acetylcholine release: role of response rate, reward density, and non-contingent stimuli. Brain Res. Cogn. Brain Res. 6, 23-36.

Himmelheber, A. M., Sarter, M., and Bruno, J. P. (2000). Increases in cortical acetylcholine release during sustained attention performance in rats. Brain Res. Cogn. Brain Res. 9 , 313-325.

Howe, M. N., and Price, I. R. (2001). Effects of transdermal nicotine on learning, memory, verbal fluency, concentration, and general health in a healthy sample at risk for dementia. Int. Psychogeriatr. 13, 465-475.

Hruska, M., Keefe, J., Wert, D., Tekinay, A. B., Hulce, J. J., Ibañez-Tallon, I., and Nishi, R. (2009). Prostate stem cell antigen is an endogenous lynx1-like prototoxin that antagonizes alpha7-containing nicotinic receptors and prevents programmed cell death of parasympathetic neurons. J. Neurosci. 29, 14847-14854.

Hruska, M., and Nishi, R. (2007). Cell-autonomous inhibition of alpha 7-containing nicotinic acetylcholine receptors prevents death of parasympathetic neurons during development. J. Neurosci. 27, 11501-11509.

Huerta, P. T., and Lisman, J. E. (1993). Heightened synaptic plasticity of hippocampal CA1 neurons during a cholinergically induced rhythmic state. Nature 364, 723-725.

Huerta, P. T., and Lisman, J. E. (1995). Bidirectional synaptic plasticity induced by a single burst during cholinergic theta oscillation in CAl in vitro. Neuron 15, 1053-1063.

Hyman, J. M., Wyble, B. P., Goyal, V., Rossi, C. A., and Hasselmo, M. E. (2003). Stimulation in hippocampal region $\mathrm{CAl}$ in behaving rats yields long-term potentiation when delivered to the peak of theta and long-term depression when delivered to the trough. J. Neurosci. 23, 11725-11731.

Hölscher, C., Anwyl, R., and Rowan, M. J. (1997). Stimulation on the positive phase of hippocampal theta rhythm induces long-term potentiation that can be depotentiated by stimulation on the negative phase in area CA1 in vivo. J. Neurosci. 17, 6470-6477.

Ikonen, S., McMahan, R., Gallagher, M., Eichenbaum, H., and Tanila, H. (2002). Cholinergic system regulation of spatial representation by the hippocampus. Hippocampus 12, 386-397.

Imamura, K., and Kasamatsu, T. (1991). Ocular dominance plasticity restored by NA infusion to aplastic visual cortex of anesthetized and paralyzed kittens. Exp. Brain Res. 87, 309-318.

Inglis, F. M., Day, J. C., and Fibiger, H. C. (1994). Enhanced acetylcholine release in hippocampus and cortex during the anticipation and consumption of a palatable meal. Neuroscience 62, 1049-1056.

Janis, L. S., Glasier, M. M., Fulop, Z., and Stein, D. G. (1998). Intraseptal injections of 192 IgG saporin produce deficits for strategy selection in spatial-memory tasks. Behav. Brain Res. 90, 23-34.

Jeewajee, A., Lever, C., Burton, S., O’Keefe, J., and Burgess, N. (2008). Environmental novelty is signaled by reduction of the hippocampal theta frequency. Hippocampus 18, 340-348.

Ji, D., Lape, R., and Dani, J. A. (2001). Timing and location of nicotinic activity enhances or depresses hippocampal synaptic plasticity. Neuron 31, 131-141.

Johnson, D. A., Zambon, N. J., and Gibbs, R. B. (2002). Selective lesion of cholinergic neurons in the medial septum by 192 IgG-saporin impairs learning in a delayed matching to position T-maze paradigm. Brain Res. 943, 132-141.

Jones, B. E., and Cuello, A. C. (1989). Afferents to the basal forebrain cholinergic cell area from pontomesencephalic-catecholamine, serotonin, and acetylcholine-neurons. Neuroscience 31, 37-61.

Kahana, M. J., Sekuler, R., Caplan, J. B., Kirschen, M., and Madsen, J. R. (1999). Human theta oscillations exhibit task dependence during virtual maze navigation. Nature 399, 781-784.

Kitagawa, H., Takenouchi, T., Azuma, R., Wesnes, K., Kramer, W., Clody, D., and Burnett, A. (2003). Safety, pharmacokinetics, and effects on cognitive function of multiple doses of GTS-21 in healthy, male volunteers. Neuropsychopharmacology 28, 542-551.

Klink, R., and Alonso, A. (1997). Muscarinic modulation of the oscillatory and repetitive firing properties of entorhinal cortex layer II neurons. J. Neurophysiol. 77, 1813-1828.

Klinkenberg, I., Sambeth, A., and Blokland, A. (2011). Acetylcholine and attention. Behav. Brain Res. 221, 430-442.

Koenig, J., Linder, A. N., Leutgeb, J. K., and Leutgeb, S. (2011). The spatial periodicity of grid cells is not sustained during reduced theta oscillations. Science 332, 592-595. 
Koller, G., Satzger, W., Adam, M., Wagner, M., Kathmann, N., Soyka, M., and Engel, R. (2003). Effects of scopolamine on matching to sample paradigm and related tests in human subjects. Neuropsychobiology 48, 87-94.

Kozak, R., Bruno, J. P., and Sarter, M. (2006). Augmented prefrontal acetylcholine release during challenged attentional performance. Cereb. Cortex 16, 9-17.

Kramis, R., Vanderwolf, C. H., and Bland, B. H. (1975). Two types of hippocampal rhythmical slow activity in both the rabbit and the rat: relations to behavior and effects of atropine, diethyl ether, urethane, and pentobarbital. Exp. Neurol. 49, 58-85.

Kremin, T., and Hasselmo, M. E. (2007). Cholinergic suppression of glutamatergic synaptic transmission in hippocampal region CA3 exhibits laminar selectivity: implication for hippocampal network dynamics. Neuroscience 149, 760-767.

Krnjevic, K., and Phillis, J. W. (1963). Acetylcholine-sensitive cells in the cerebral cortex. J. Physiol. 166, 296-327.

Kroker, K. S., Rast, G., and Rosenbrock, H. (2011). Differential effects of subtype-specific nicotinic acetylcholine receptor agonists on early and late hippocampal LTP. Eur. J. Pharmacol. 671, 26-32.

Labarca, C., Schwarz, J., Dashpande, P., Schwarz, S., Nowak, M., Fonck, C., Nashmi, R., Kofuj, P., Dang, H., Shi, W., Fidan, M., Khakh, B., Chen, Z., Bowers, B. J., Boulter, J., Wehner, J. M., and Lester, H. A. (2001). Point mutant mice with hypersensitive alpha 4 nicotinic receptors show dopaminergic deficits and increased anxiety. Proc. Natl. Acad. Sci. U.S.A. 98, 2786-2791.

Lagostena, L., Trocme-Thibierge, C., Morain, P., and Cherubini, E. (2008). The partial alpha7 nicotine acetylcholine receptor agonist S 24795 enhances long-term potentiation at CA3-CA1 synapses in the adult mouse hippocampus. Neuropharmacology 54, 676-685.

Leanza, G., Nilsson, O. G., Wiley, R. G., and Björklund, A. (1995). Selective lesioning of the basal forebrain cholinergic system by intraventricular 192 IgG-saporin: behavioural, biochemical and stereological studies in the rat. Eur. J. Neurosci. 7, 329-343.

Lee, M. G., Chrobak, J. J., Sik, A., Wiley, R. G., and Buzsáki, G. (1994). Hippocampal theta activity following selective lesion of the septal cholinergic system. Neuroscience 62, 1033-1047.

Leung, L. S., Shen, B., Rajakumar, N., and Ma, J. (2003). Cholinergic activity enhances hippocampal longterm potentiation in CAl during walking in rats. J. Neurosci. 23, 9297-9304.

Linster, C., and Hasselmo, M. (1997). Modulation of inhibition in a model of olfactory bulb reduces overlap in the neural representation of olfactory stimuli. Behav. Brain Res. 84, 117-127.

Linster, C., Wyble, B. P., and Hasselmo M. E. (1999). Electrical stimulation of the horizontal limb of the diagonal band of broca modulates population EPSPs in piriform cortex. J. Neurophysiol. 81, 2737-2742.

Madison, D. V., and Nicoll, R. A. (1984). Control of the repetitive discharge of rat CA 1 pyramidal neurones in vitro. J. Physiol. 354, 319-331.

Mansvelder, H. D., van Aerde, K. I., Couey, J. J., and Brussaard, A. B. (2006). Nicotinic modulation of neuronal networks: from receptors to cognition. Psychopharmacology 184, 292-305.

Marrosu, F., Portas, C., Mascia, M. S., Casu, M. A., Fa, M., Giagheddu, M., Imperato, A., and Gessa, G. L. (1995). Microdialysis measurement of cortical and hippocampal acetylcholine release during sleep-wake cycle in freely moving cats. Brain Res. 671, 329-332.

Maskos, U., Molles, B. E., Pons, S. Besson, M., Guiard, B. P., Guilloux, J. P., Evrard, A., Cazala, P., Cormier, A., Mameli-Engvall, M., Dufour, N., Cloëz-Tayarani, I., Bemelmans, A. P., Mallet, J., Gardier, A. M. David, V., Faure, P., Granon, S., and Changeux, J. P. (2005). Nicotine reinforcement and cognition restored by targeted expression of nicotinic receptors. Nature 436, 103-107.

McGaughy, J., Kaiser, T., and Sarter, M. (1996). Behavioral vigilance following infusions of 192 IgG-saporin into the basal forebrain: selectivity of the behavioral impairment and relation to cortical AChE-positive fiber density. Behav. Neurosci. 110 247-265.

McGaughy, J., Koene, R. A., Eichenbaum, H., and Hasselmo, M. E. (2005). Cholinergic deafferentation of the entorhinal cortex in rats impairs encoding of novel but not familiar stimuli in a delayed nonmatch-to-sample task. J. Neurosci. 25, 10273-10281.

McLennan, H., and Miller, J. J. (1974a). The hippocampal control of neuronal discharges in the septum of the rat. J. Physiol. 237, 607-624.

McLennan, H., and Miller, J. J. (1974b). Gamma-aminobutyric acid and inhibition in the septal nuclei of the rat. J. Physiol. 237, 625-633.

McMahan, R. W., Sobel, T. J., and Baxter, M. G. (1997). Selective immunolesions of hippocampal cholinergic input fail to impair spatial working memory. Hippocampus 7, 130-136.

McNaughton, B. L., Barnes, C. A., Gerrard, J. L., Gothard, K., Jung, M. W., Knierim, J. J., Kudrimoti, H., Qin, Y., Skaggs, W. E., Suster, M., and Weaver, K. L. (1996). Deciphering the hippocampal polyglot: the hippocampus as a path integration system. J. Exp. Biol. 199, 173-185.

McNaughton, B. L., Battaglia, F. P. Jensen, O., Moser, E. I., and Moser, M. B. (2006). Path integration and the neural basis of the 'cognitive map'. Nat. Rev. Neurosci. 7, 663-678.

McQuiston, A. R., and Madison, D. V. (1999). Nicotinic receptor activation excites distinct subtypes of interneurons in the rat hippocampus. J. Neurosci. 19, 2887-2896.

Menschik, E. D., and Finkel, L. H. (1999). Cholinergic neuromodulation and Alzheimer's disease: from single cells to network simulations Prog. Brain Res. 121, 19-45.

Mesulam, M. M., Mufson, E. J., Wainer, B. H., and Levey, A. I. (1983a). Central cholinergic pathways in the rat: an overview based on an alternative nomenclature (Ch1-Ch6) Neuroscience 10, 1185-1201.

Mesulam, M. M., Mufson, E. J., Levey, A. I., and Wainer, B. H. (1983b) Cholinergic innervation of cortex by the basal forebrain: cytochemistry and cortical connections of the septal area, diagonal band nuclei, nucleus basalis (substantia innominata), and hypothalamus in the rhesus monkey. J. Comp. Neurol. 214, 170-197.

Mike, A., Castro, N. G., and Albuquerque, E. X. (2000). Choline and acetylcholine have similar kinetic properties of activation and desensitization on the alpha7 nicotinic receptors in rat hippocampal neurons. Brain Res. 882, 155-168.

Miller, V. M., and Best, P. J. (1980). Spatial correlates of hippocampal unit activity are altered by lesions of the fornix and endorhinal cortex. Brain Res. 4, 311-323.

Miwa, J. M., Freedman, R., and Lester, H. A. (2011). Neural systems governed by nicotinic acetylcholine receptors: emerging hypotheses. Neuron 70, 20-33.
Mogenson, G. J., Swanson, L. W., and Wu, M. (1983). Neural projections from nucleus accumbens to globus pallidus, substantia innominata, and lateral preoptic lateral hypothalamic area: an anatomical and electrophysiological investigaion in the rat. J. Neurosci. 3, 189-202.

Monmaur, P., Collet, A., Puma, C. Frankel-Kohn, L., and Sharif, A. (1997). Relations between acetylcholine release and electrophysiological characteristics of theta rhythm: a microdialysis study in the urethane-anesthetized rat hippocampus. Brain Res. Bull. 42, 141-146.

Monosov, I. E., Sheinberg, D. L., and Thompson, K. G. (2010). Paired neuron recordings in the prefrontal and inferotemporal cortices reveal that spatial selection precedes object identification during visual search. Proc. Natl. Acad. Sci. U.S.A. 107, 13105-13110.

Moore, H., Sarter, M., and Bruno, J. P. (1992). Age-dependent modulation of in vivo cortical acetylcholine release by benzodiazepine receptor ligands. Brain Res. 596, 17-29.

Morris, R. G., Garrud, P., Rawlins, J. N., and O'Keefe, J. (1982). Place navigation impaired in rats with hippocampal lesions. Nature 297, 681-683.

Moser, E. I., Kropff, E., and Moser, M. B. (2008). Place cells, grid cells, and the brain's spatial representation system. Annu. Rev. Neurosci. 31, 69-89.

Mrzljak, L., Levey, A. I., and GoldmanRakic, P. S. (1993). Association of $\mathrm{m} 1$ and $\mathrm{m} 2$ muscarinic receptor proteins with asymmetric synapses in the primate cerebral cortex: morphological evidence for cholinergic modulation of excitatory neurotransmission. Proc. Natl. Acad. Sci. U.S.A. 90, 5194-5198.

Muller, R. U., and Kubie, J. L. (1987). The effects of changes in the environment on the spatial firing of hippocampal complex-spike cells. J. Neurosci. 7, 1951-1968.

Murphy, P. C., and Sillito, A. M. (1991). Cholinergic enhancement of direction selectivity in the visual cortex of the cat. Neuroscience 40, 13-20.

Newman, E. L., and Hasselmo, M. E. (2011). Grid cells and acetylcholine: role of muscarinic modulation in theta rhythmicity and spatial tuning of grid cell firing fields. Soc Neurosci. Abstr. 730.07 .

Newman, E. L., and Norman, K. A. (2010). Moderate excitation leads to weakening of perceptual representations. Cereb. Cortex 20, 2760-2770. 
Newman, L. A., and McGaughy, J. (2008). Cholinergic deafferentation of prefrontal cortex increases sensitivity to cross-modal distractors during a sustained attention task. J. Neurosci. 28, 2642-2650.

Norman, K. A., Newman, E. L., Detre, G. J., and Polyn, S. M. (2006). How inhibitory oscillations can train neural networks and punish competitors. Neural Comput. 18, 1577-1610.

Norman, K. A., Newman, E. L., and Detre, G. (2007). A neural network model of retrieval-induced forgetting. Psychol. Rev. 114, 887-953.

Norman, K. A., Newman, E. L., and Perotte, A. J. (2005). Methods for reducing interference in the complementary learning systems model: oscillating inhibition and autonomous memory rehearsal. Neural Netw. 18, 1212-1228.

O'Keefe, J., and Dostrovsky, J. (1971). The hippocampus as a spatial map. Preliminary evidence from unit activity in the freely-moving rat. Brain Res. 34, 171-175.

O'Keefe, J., and Recce, M. L. (1993). Phase relationship between hippocampal place units and the EEG theta rhythm. Hippocampus 3, 317-330.

Ohno, M., Yamamoto, T., and Watanabe, S. (1994). Blockade of hippocampal M1 muscarinic receptors impairs working memory performance of rats. Brain Res. 650 , 260-266.

Ondrejcak, T., Wang, Q., Kew, J. N. C., Virley, D. J., Upton, N., Anwyl, R., and Rowan, M. J. (2012). Activation of $\alpha 7$ nicotinic acetylcholine receptors persistently enhances hippocampal synaptic transmission and prevents $A B$-mediated inhibition of LTP in the rat hippocampus. Eur. J. Pharmacol. 677, 63-70.

Ostfeld, A. M., and Aruguete, A. (1962). Central nervous system effects of hyoscine in man. J. Pharmacol. Exp. Ther. 137, 133-139.

Otto, T., and Eichenbaum, H. (1992). Complementary roles of the orbital prefrontal cortex and the perirhinal-entorhinal cortices in an odor-guided delayed-nonmatchingto-sample task. Behav. Neurosci. 106, 762-775.

Ovsepian, S. V., Anwyl, R., and Rowan, M. J. (2004). Endogenous acetylcholine lowers the threshold for long-term potentiation induction in the CA1 area through muscarinic receptor activation: in vivo study. Eur. J. Neurosci. 20, 1267-1275.

Padlubnaya, D., Galizio, M., Pitts, R. C., and Keith, J. R. (2005).
Chlordiazepoxide interactions with scopolamine and dizocilpine: novel cooperative and antagonistic effects on spatial learning. Behav. Neurosci. 119, 1331-1338.

Parikh, V., Kozak, R., Martinez, V., and Sarter, M. (2007). Prefrontal acetylcholine release controls cue detection on multiple timescales. Neuron 56, 141-154.

Parikh, V., Pomerleau, F., Huettl, P., Gerhardt, G. A., Sarter, M., and Bruno, J. P. (2004). Rapid assessment of in vivo cholinergic transmission by amperometric detection of changes in extracellular choline levels. Eur. J. Neurosci. 20, 1545-1554.

Passetti, F., Dalley, J. W., O'Connell, M. T., Everitt, B. J., and Robbins, T. W. (2000). Increased acetylcholine release in the rat medial prefrontal cortex during performance of a visual attentional task. Eur. J. Neurosci. 12, 3051-3058.

Passingham, R. (1975). Delayed matching after selective prefrontal lesions in monkeys (Macaca mulatta). Brain Res. 92, 89-102.

Patil, M. M., Linster, C., Lubenov, E., and Hasselmo, M. E. (1998). Cholinergic agonist carbachol enables associative long-term potentiation in piriform cortex slices. J. Neurophysiol. 80, 2467-2474.

Paylor, R., Nguyen, M., Crawley, J. N., Patrick, J., Beaudet, A., and OrrUrtreger, A. (1998). Alpha7 nicotinic receptor subunits are not necessary for hippocampal-dependent learning or sensorimotor gating: a behavioral characterization of Acra7-deficient mice. Learn. Mem. 5, 302-316.

Penton, R. E., Quick, M. W., and Lester, R. A. J. (2011). Short- and long-lasting consequences of in vivo nicotine treatment on hippocampal excitability. J. Neurosci. 31, 2584-2594.

Petersen, R. C. (1977). Scopolamine induced learning failures in man. Psychopharmacology 52, 283-289.

Picciotto, M. R., Zoli, M., Léna, C., Bessis, A., Lallemand, Y., Le Novère, N., Vincent, P., Pich, E. M., Brûlet, P., and Changeux, J. P. (1995). Abnormal avoidance learning in mice lacking functional high-affinity nicotine receptor in the brain. Nature 374, 65-67.

Pichat, P., Bergis, O. E., Terranova, J. P., Urani, A., Duarte, C., Santucci, V., Gueudet, C., Voltz, C., Steinberg, R., Stemmelin, J., Oury-Donat, F., Avenet, P., Griebel, G., and
Scatton, B. (2007). SSR180711, a novel selective alpha7 nicotinic receptor partial agonist: (II) efficacy in experimental models predictive of activity against $\operatorname{cog}$ nitive symptoms of schizophrenia. Neuropsychopharmacology 32 17-34.

Pidoplichko, V. I., Noguchi, J., Areola, O. O., Liang, Y., Peterson, J., Zhang, T., and Dani, J. A. (2004). Nicotinic cholinergic synaptic mechanisms in the ventral tegmental area contribute to nicotine addiction. Learn. Mem. 11, 60-69.

Raghavachari, S., Kahana, M. J., Rizzuto, D. S., Caplan, J. B., Kirschen, M. P., Bourgeois, B., Madsen, J. R., and Lisman, J. E. (2001). Gating of human theta oscillations by a working memory task. J. Neurosci. 9, 3175-3183.

Robbins, T. W., Semple, J., Kumar, R., Truman, M. I., Shorter, J., Ferraro, A., Fox, B., McKay, G., and Matthews, K. (1997). Effects of scopolamine on delayed-matchingto-sample and paired associates tests of visual memory and learning in human subjects: comparison with diazepam and implications for dementia. Psychopharmacology 134, 95-106.

Roberts, M. J., and Thiele, A. (2008). Spatial integration and its moderation by attention and acetylcholine. Front. Biosci. 13, 3742-3759.

Roberts, M. J., Zinke, W., Guo, K., Robertson, R., McDonald, J. S., and Thiele, A. (2005). Acetylcholine dynamically controls spatial integration in marmoset primary visual cortex. J. Neurophysiol. 93, 2062-2072.

Rye, D. B., Saper, C. B., Lee, H. J., and Wainer, B. H. (1987). Pedunculopontine tegmental nucleus in the rat: cytoarchitecture, cytochemistry and some extrapyramidal connections of the mesopontine tegmentum. J. Comp. Neurol. 259, 483-528.

Sarter, M., Bruno, J. P., and Givens, B. (2003). Attentional functions of cortical cholinergic inputs: what does it mean for learning and memory? Neurobiol. Learn. Mem. 80, 245-256.

Sarter, M., Bruno, J. P., Givens, B., Moore, H., McGaughy, J., and McMahon, K. (1996). Neuronal mechanisms mediating druginduced cognition enhancement: cognitive activity as a necessary intervening variable. Brain Res. Cogn. Brain Res. 3, 329-343.

Sarter, M., Gehring, W. J., and Kozak, R. (2006). More attention must be paid: the neurobiology of attentional effort. Brain Res. Rev $51,145-160$.

Sarter, M., Hasselmo, M. E., Bruno, J. P., and Givens, B. (2005). Unraveling the attentional functions of cortical cholinergic inputs: interactions between signal-driven and cognitive modulation of signal detection. Brain Res. Brain Res. Rev. 48, 98-111.

Sato, H., Hata, Y., Masui, H., and Tsumoto, T. (1987). A functional role of cholinergic innervation to neurons in the cat visual cortex. J. Neurophysiol. 58, 765-780.

Schallert, T., Overstreet, D. H., and Yamamura, H. I. (1980). Muscarinic receptor binding and behavioral effects of atropoine following chronic catecholamine depletion or acetylcholinesterase inhibition in rats. Pharmacol. Biochem. Behav. 13, 187-192.

Schon, K., Atri, A., Hasselmo, M. E., Tricarico, M. D., Lopresti, M. L., and Stern, C. E. (2005). Scopolamine reduces persistent activity related to long-term encoding in the parahippocampal gyrus during delayed matching in humans. J. Neurosci. 25, 9112-9123.

Schon, K., Hasselmo, M. E., Lopresti, M. L., Tricarico, M. D., and Stern, C. E. (2004). Persistence of parahippocampal representation in the absence of stimulus input enhances long-term encoding: a functional magnetic resonance imaging study of subsequent memory after a delayed match-to-sample task. J. Neurosci. 24, 11088-11097.

Schon, K., Tinaz, S., Somers, D. C., and Stern, C. E. (2008). Delayed match to object or place: an event-related fMRI study of short-term stimulus maintenance and the role of stimulus pre-exposure. Neuroimage 39, 857-872.

Sederberg, P. B., Kahana, M. J., Howard, M. W., Donner, E. J., and Madsen, J. R. (2003). Theta and gamma oscillations during encoding predict subsequent recall. J. Neurosci. 23, 10809-10814.

Shapiro, M. L., Simon, D. K., Olton, D. S., Gage, F. H., Nilsson, O., and Björklund, A. (1989). Intrahippocampal grafts of fetal basal forebrain tissue alter place fields in the hippocampus of rats with fimbria-fornix lesions. Neuroscience 32, 1-18.

Shirey, J. K., Xiang, Z., Orton, D., Brady, A. E., Johnson, K. A., Williams, R., Ayala, J. E., Rodriguez, A. L., Wess, J., Weaver, D., Niswender, C. M., and Conn, P. J. (2008). An allosteric potentiator of $\mathrm{M} 4 \mathrm{mAChR}$ modulates hippocampal synaptic 
transmission. Nat. Chem. Biol. 4, 42-50.

Silver, M. A., Shenhav, A., and D’Esposito, M. (2008). Cholinergic enhancement reduces spatial spread of visual responses in human early visual cortex. Neuron 60, 904-914.

Stanley, E. M., Wilson, M. A., and Fadel, J. R. (2012). Hippocampal neurotransmitter efflux during onetrial novel object recognition in rats. Neurosci. Lett. 511, 38-42.

Steffenach, H. A., Witter, M., Moser, M. B., and Moser, E. I. (2005). Spatial memory in the rat requires the dorsolateral band of the entorhinal cortex. Neuron 45, 301-313.

Stern, C. E., Sherman, S. J., Kirchhoff, B. A., and Hasselmo, M. E. (2001). Medial temporal and prefrontal contributions to working memory tasks with novel and familiar stimuli. Hippocampus 11, 337-346.

Stewart, M., and Fox, S. E. (1990). Do septal neurons pace the hippocampal theta rhythm? Trends Neurosci. 13, 163-168.

Sudweeks, S. N., and Yakel, J. L. (2000). Functional and molecular characterization of neuronal nicotinic ACh receptors in rat CA1 hippocampal neurons. J. Physiol. 527, 515-528.

Sutherland, R. J., Whishaw, I. Q., and Regehr, J. C. (1982). Cholinergic receptor blockade impairs spatial localization by use of distal cues in the rat. J. Comp. Physiol. Psychol. 96, 563-573.

Suzuki, W. A., Miller, E. K., and Desimone, R. (1997). Object and place memory in the macaque entorhinal cortex. J. Neurophysiol. 78, 1062-1081.

Tang, Y., Mishkin, M., and Aigner, T. G. (1997). Effects of muscarinic blockade in perirhinal cortex during visual recognition. Proc. Natl. Acad. Sci. U.S.A. 94, 12667-12669.

Thiel, C. M., Huston, J. P., and Schwarting, R. K. (1998). Hippocampal acetylcholine and habituation learning. Neuroscience 85, 1253-1262.

Thomas, E., Snyder, P. J., Pietrzak, R. H., Jackson, C. E., Bednar, M., and Maruff, P. (2008). Specific impairments in visuospatial working and short-term memory following low-dose scopolamine challenge in healthy older adults. Neuropsychologia 46, 2476-2484.

Toth, K., Borhegyi, Z., and Freund, T. F. (1993). Postsynaptic targets of GABAergic hippocampal neurons in the medial septum diagonal band of broca complex. J. Neurosci. 13, 3712-3724.

Treinin, M., and Chalfie, M. (1995). A mutated acetylcholine receptor subunit causes neuronal degeneration in C. elegans. Neuron 14, 871-877.

Tremblay, N., Warren, R. A., and Dykes, R. W. (1990). Electrophysiological studies of acetylcholine and the role of the basal forebrain in the somatosensory cortex of the cat. II. Cortical neurons excited by somatic stimuli. J. Neurophysiol. 64, 1212-1222.

Tu, B., Gu, Z., Shen, J. X., Lamb, P. W., and Yakel, J. L. (2009). Characterization of a nicotinesensitive neuronal population in rat entorhinal cortex. J. Neurosci. 29, 10436-10448.

Turchi, J., and Sarter, M. (1997). Cortical acetylcholine and processing capacity: effects of cortical cholinergic deafferentation on crossmodal divided attention in rats. Brain Res. Cogn. Brain Res. 6, 147-158.

Umbriaco, D., Garcia, S., Beaulieu, C., and Descarries, L. (1995). Relational features of acetylcholine, noradrenaline, serotonin and GABA axon terminals in the stratum radiatum of adult rat hippocampus (CA1). Hippocampus 5, 605-620.

Umbriaco, D., Watkins, K. C., Descarries, L., Cozzari, C., and Hartman, B. K. (1994). Ultrastructural and morphometric features of the acetylcholine innervation in adult rat parietal cortex: an electron microscopic study in serial sections. J. Comp. Neurol 348, 351-373.

Vanderwolf, C. H. (1969). Hippocampal electrical activity and voluntary movement in the rat. Electroencephalogr. Clin. Neurophysiol. 26, 407-418.

Vertes, R., and Kocsis, B. (1997). Brainstem-diencephalo-septohippocampal systems controlling the theta rhythm of the hippocampus. Neuroscience 81, 893-926.

Vinogradova, O. S. (1995). Expression, control, and probable functional significance of the neuronal thetarhythm. Prog. Neurobiol. 45, 523-583.

Voytko, M. L., Olton, D. S., Richardson, R. T., Gorman, L. K., Tobin, J. R., and Price, D. L. (1994). Basal forebrain lesions in monkeys disrupt attention but not learning and memory. J. Neurosci. 14, 167-186.
Vuckovich, J. A., Semel, M. E., and Baxter, M. G. (2004). Extensive lesions of cholinergic basal forebrain neurons do not impair spatial working memory. Learn. Mem. 11, 87-94.

West, M., Söderman, A., Mikkelsen, J. D., Christensen, D., and Jensen, M. S. (2010). Activation of nicotinic alpha 7 acetylcholine receptor enhances long-term potentiation in wild-type mice, but not APPswe/PS1deltaE9 mice. Alzheimer's Dement. 6, S400.

Wiley, R. G., Oeltmann, T. N. and Lappi, D. A. (1991). Immunolesioning: selective destruction of neurons using immunotoxin to rat NGF receptor. Brain Res. 562, 149-153.

Wilson, I. A., Ikonen, S., McMahan, R. W., Gallagher, M., Eichenbaum, H., and Tanila, H. (2003). Place cell rigidity correlates with impaired spatial learning in aged rats. Neurobiol. Aging 24, 297-305.

Winters, B. D., and Bussey, T. J. (2005). Transient inactivation of perirhinal cortex disrupts encoding, retrieval, and consolidation of object recognition memory. J. Neurosci. 25, 52-61.

Xu, J., Zhu, Y., and Heinemann, S. F. (2006). Identification of sequence motifs that target neuronal nicotinic receptors to dendrites and axons. J. Neurosci. 26, 9780-9793.

Yoshida, M., Fransen, E., and Hasselmo, M. E. (2008). mGluRdependent persistent firing in entorhinal cortex layer III neurons. Eur. J. Neurosci. 28, 1116-1126.

Yoshida, M., Giocomo, L. M., Boardman, I., and Hasselmo, M. E. (2011). Frequency of subthreshold oscillations at different membrane potential voltages in neurons at different anatomical positions on the dorsoventral axis in the rat medial entorhinal cortex. J. Neurosci. 31, 12683-12694.

Young, B. J., Otto, T., Fox, G. D., and Eichenbaum, H. (1997). Memory representation within the parahippocampal region. J. Neurosci. 17, 5183-5195.

Young, J. W., Finlayson, K., Spratt, C., Marston, H. M., Crawford, N., Kelly, J. S., and Sharkey, J. (2004). Nicotine improves sustained attention in mice: evidence for involvement of the alpha7 nicotinic acetylcholine receptor. Neuropsychopharmacology 29, 891-900.

Yu, A. J., and Dayan, P. (2002). Acetylcholine in cortical inference. Neural Netw. 15, 719-730.
Yu, A. J., and Dayan, P. (2005). Uncertainty, neuromodulation, and attention. Neuron 46, 681-692.

Yun, S. H., Cheong, M. Y., Mook-Jung, I., Huh, K., Lee, C., and Jung, M. W. (2000). Cholinergic modulation of synaptic transmission and plasticity in entorhinal cortex and hippocampus of the rat. Neuroscience 97, 671-676.

Zhang, H., Lin, S. C., and Nicolelis, M. A. (2010). Spatiotemporal coupling between hippocampal acetylcholine release and theta oscillations in vivo. J. Neurosci. 30, 13431-13440.

Zilli, E. A., and Hasselmo, M. E. (2010). Coupled noisy spiking neurons as velocity-controlled oscillators in a model of grid cell spatial firing. J. Neurosci. 30, 13850-13860.

Zola-Morgan, S., and Squire, L. R. (1993). Neuroanatomy of memory. Annu. Rev. Neurosci. 16, 547-563.

Záborsky, L., Gaykema, R. P., Swanson, D. J., and Cullinan, W. E. (1997). Cortical input to the basal forebrain. Neuroscience 79, 1051-1078.

Záborsky, L., and Cullinan, W. E. (1992). Projections from the nucleus accumbens to cholinergic neurons of the ventral pallidum: a correlated light and electron microscopic double-immunolabeling study in a rat. Brain Res. 570, 92-101.

Conflict of Interest Statement: The authors declare that the research was conducted in the absence of any commercial or financial relationships that could be construed as a potential conflict of interest.

Received: 02 March 2012; accepted: 21 May 2012; published online: 13 June 2012.

Citation: Newman EL, Gupta K, Climer $J R$, Monaghan CK and Hasselmo ME (2012) Cholinergic modulation of cognitive processing: insights drawn from computational models. Front. Behav. Neurosci. 6:24. doi: 10.3389/fnbeh. 2012.00024

Copyright (c) 2012 Newman, Gupta, Climer, Monaghan and Hasselmo. This is an open-access article distributed under the terms of the Creative Commons Attribution Non Commercial License, which permits non-commercial use, distribution, and reproduction in other forums, provided the original authors and source are credited. 